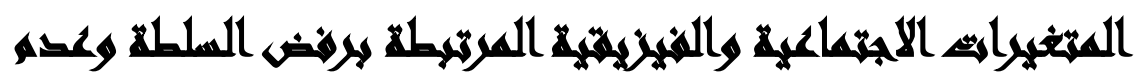

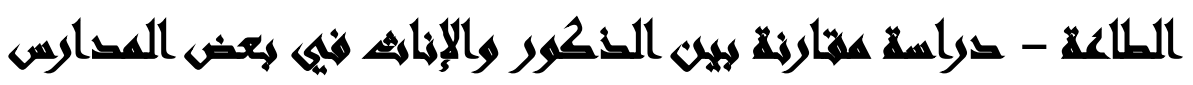 اللرسمية للغاهت
}

$[1 \cdot]$

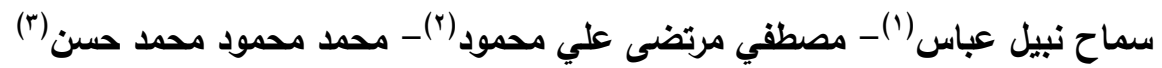

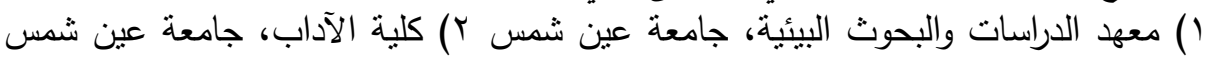
r) المعهد العالي للخدمة الاجتماعية بالقاهرة

\section{المستخلس}

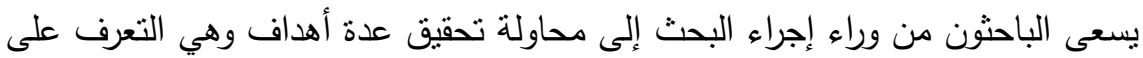

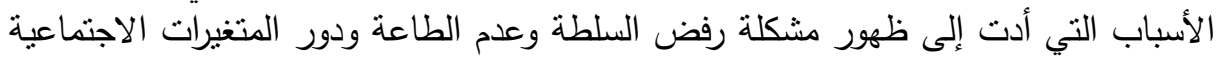

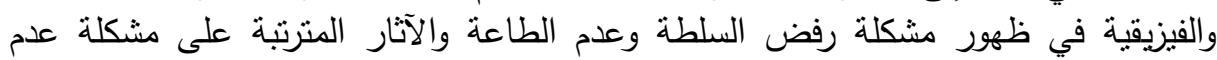

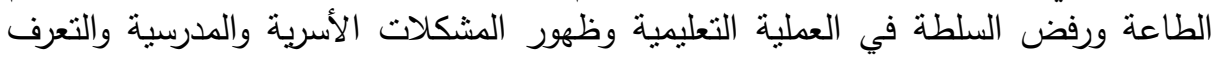

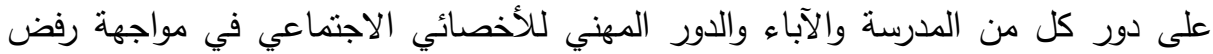

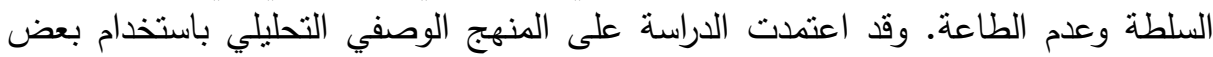

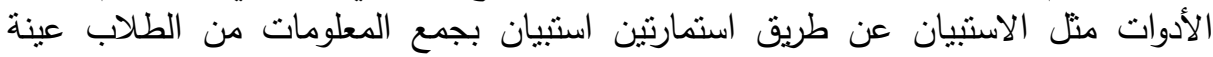

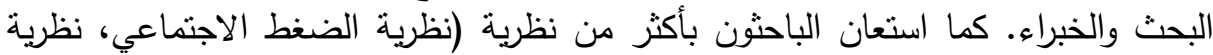

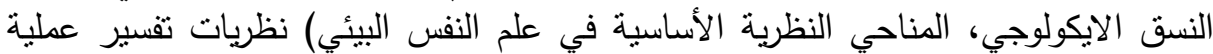

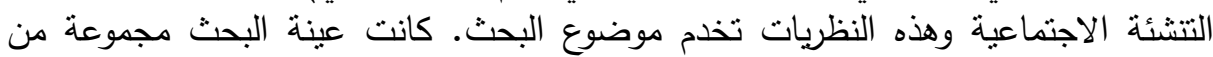

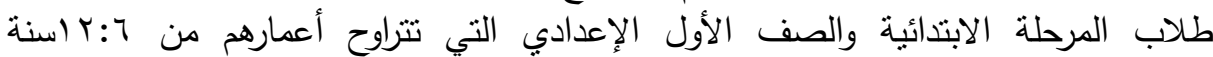

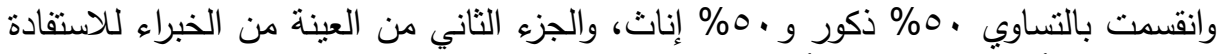

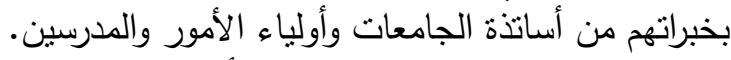

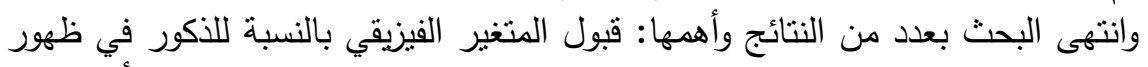

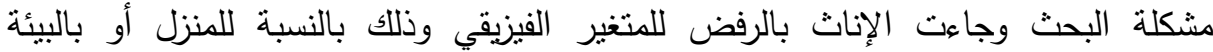
المدرسية فجاءت بالرفض لدور المتغيرات الفيزيقية بالنسبة للأكور . أما بالنسبة للإناث الئاث أيضًا

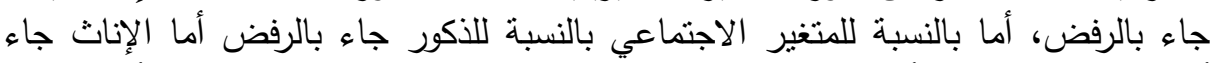

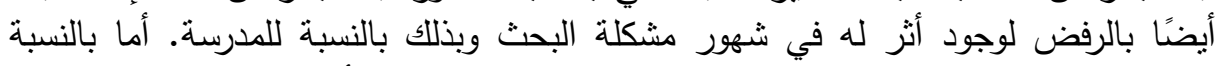

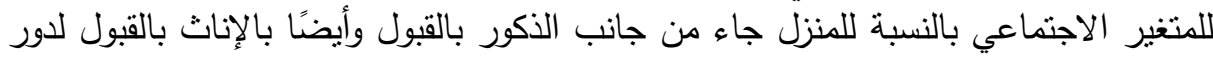
المتغير الاجتماعي وأثره في ظهور مشكلة البحث، أما بالنسبة لدور الأبناء الأسرة والآباء لمواجهة

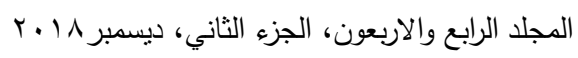


المشكلة فتأكد من ضرورة استخدام أساليب التتشئة الاجتماعية السليمة في التعامل مع الأولاد

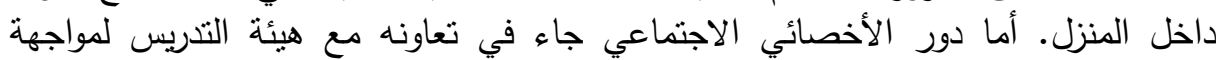

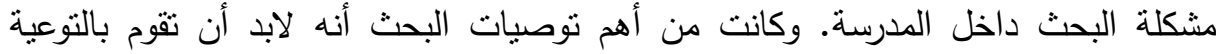

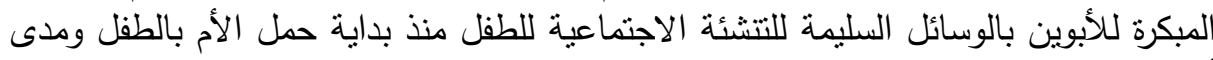

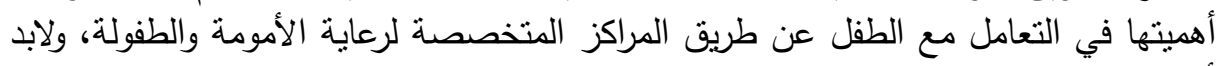
أن تقوم وزارة التربية والتعليم دورات تدريبية للمدرسين لتدريبهم على كيفية فهر خصائص التص كل

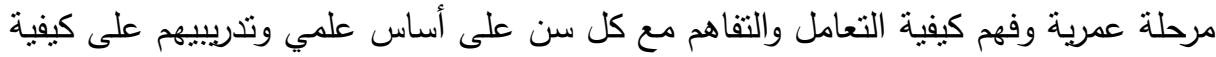

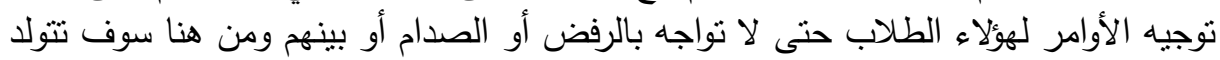

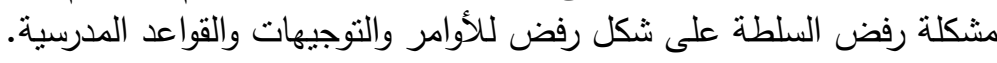

\section{Xation}

مما لا شك فيه أن في الآونة الأخيرة ظهرت مشكلة قوية في الددرسة والمنازل العربية

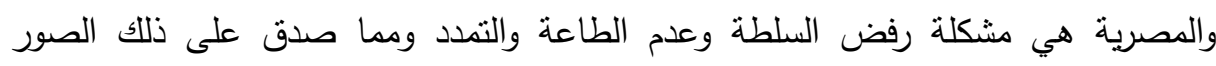

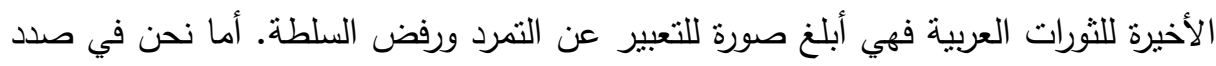

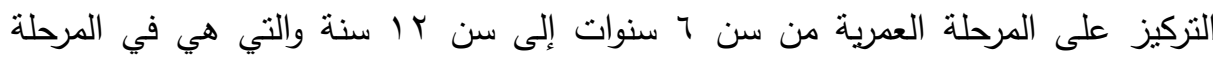

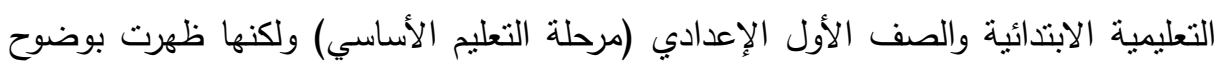
بأشكال عدة وأصبحت تهدد استقرار وأمن الهجتمع الهصري والأسرة الهصرية.

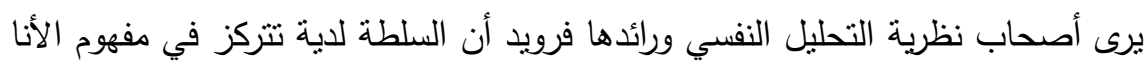

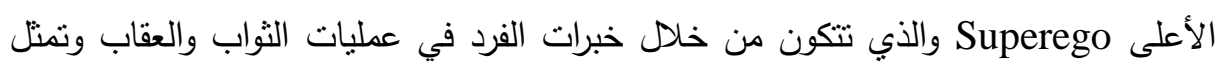
القيم والمعايير الخلقية والأوامر والنواهي، من خلا هذ هذا نقيم علاقات بالمحيطين به ويعد هذا

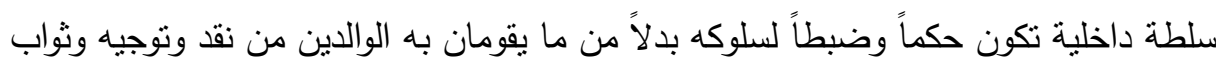

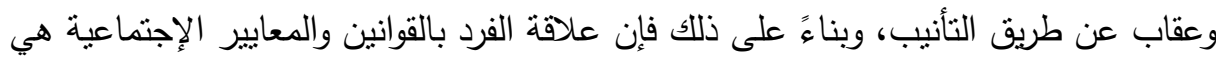
علاقة بالأنا الأعلى والتي نشأت من سلطة الوالدين والتي يرى فرويد أن هذه السلطة الوالدية

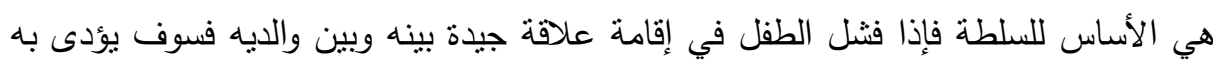
إلى نتائج سلبية قد تظل معه مدى الحياة بحيث إذا عجز الطفل عن إجنياز المرحلة الأوديبية

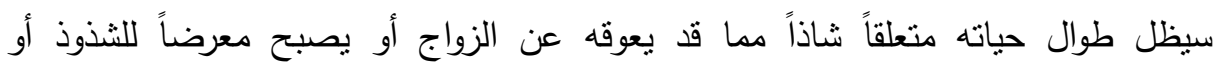

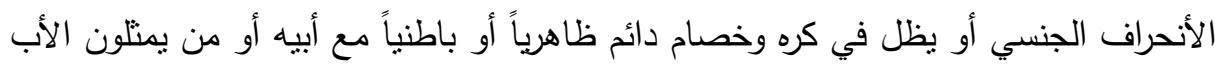


في نظرة أي من بيده السلطة والنفوذ مثل سلطة الرؤساء أو المرشحين أو الأساتذة في

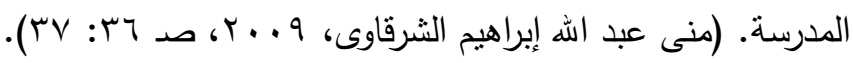

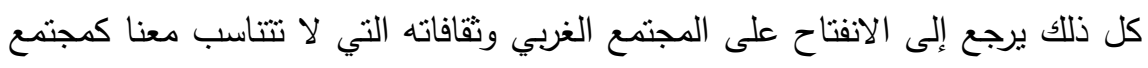
عربي ومصري وينعكس ذلك على المجتمعات العربية والمصرية بعدم الاستقرار وعدم التوازن التحن

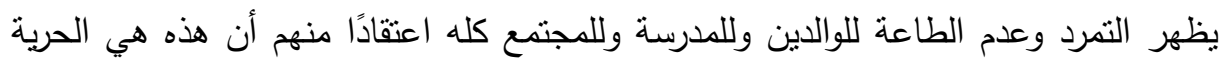

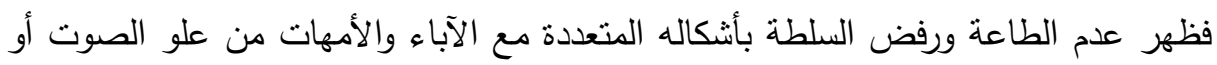
رفض الانصياع للأوامر أو الاحتجاج على كل شيء لمجرد الاحتجاج والرفض ومما لا شك بك الته فيه أنها ظهرت أيضًا في المدرسة بشكل واضح ويترتب برفض السلطة وعدم الطاعة مثل التل

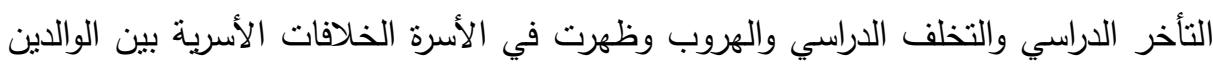
قد تؤدي إلى الانفصال بين الوالدين.

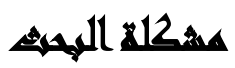

فى الآونة الأخيرة عانت المدرسة والأسرة العربية والمصرية من مشكلة كانت موجودة

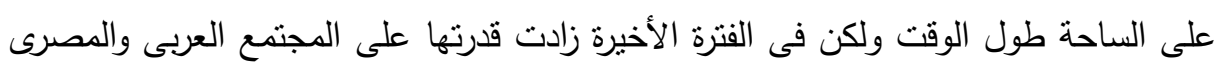

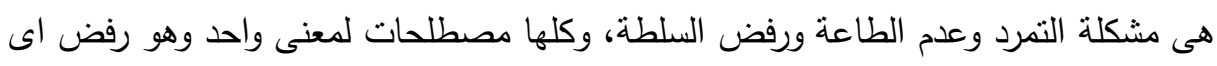
قواعد مجتمعية أو أسرية ثُرض وضم على الأولاد.

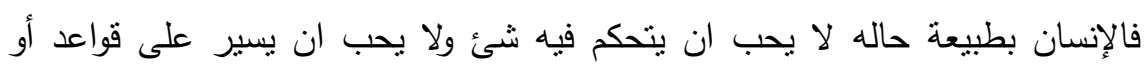
قوانين تُقيَض من حريته. إذا اعتبرنا عدم الطاعة ورفض السلطة شئ طبيعى فى مرحلة المراهقة فلا جديد فى ذلك فهى سمات مرحلة عمرية وقد أكدت ذلك نظرية أريكسون ونظرية التحليل النفسى.

الإبتدائية فى التعليم لأن من سمات هذه المرحلة العمريه حسب النظريتين السابقتين ان

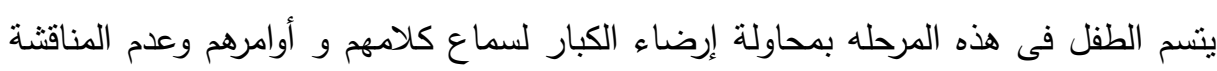

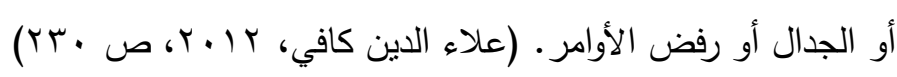




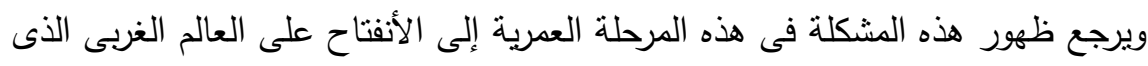

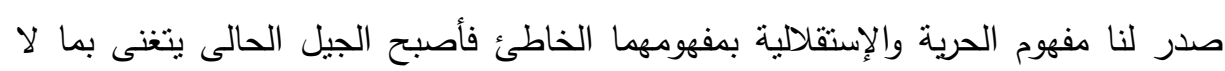
يتماشى مع ثقافتتا وعاداتتا العربية والمصرية.

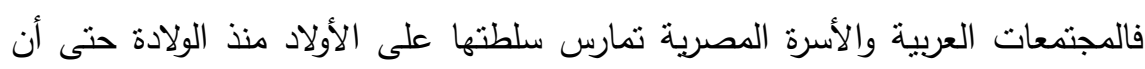

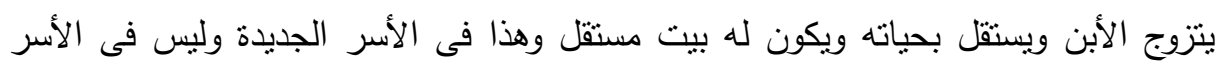

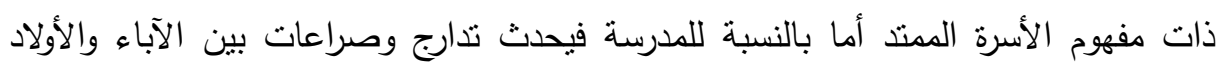

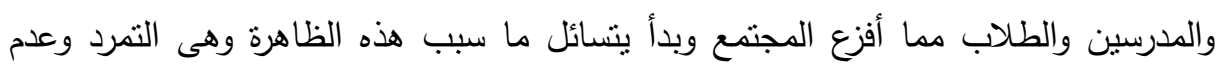
الطاعة ورفض السلطة.

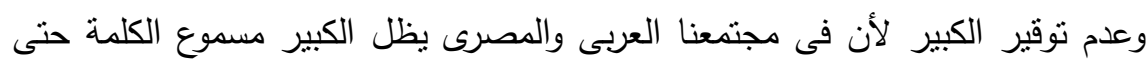

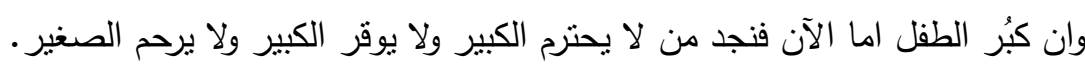

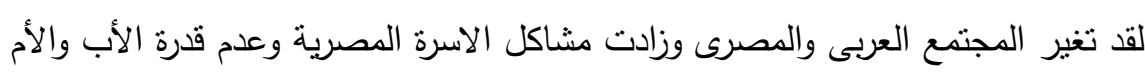

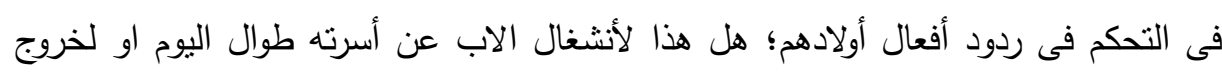

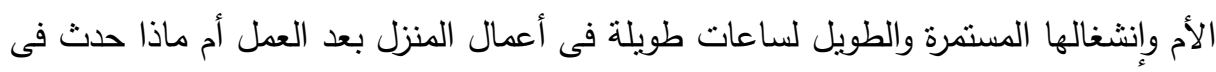

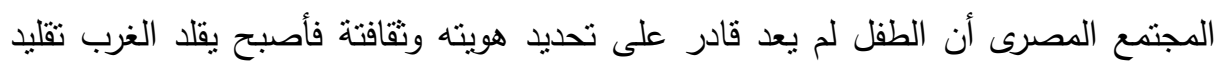

\section{أسهلم البهيث}

1. ما الأسباب التي أدت إلى ظهور مشكلة عدم الطاعة ورفض السلطة؟

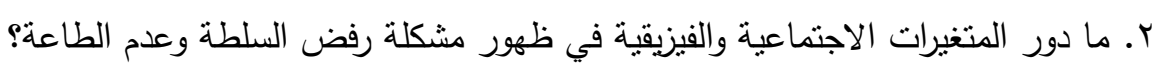
r. ما الآثار المترتبة على مشكلة رفض السلطة وعدم الطاعة في العملية التعليمية وظهور

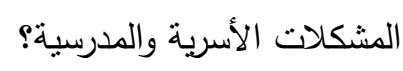

ع. ما دور كلًا من المدرسة والآباء في مواجهة مثكلة رفض السطبة والطة وعدم الطاعة؟

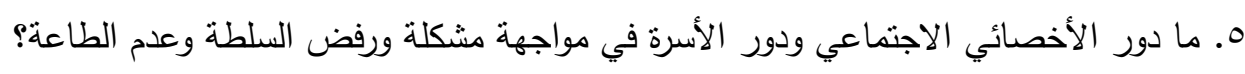




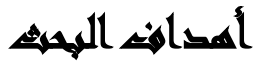

1. التعرف على الأسباب التي أدت إلى ظهور مشكلة رفض السلطة وعدم الطاعة. r. التعرف على دور المتغيرات الاجتماعية والفيزيقية في ظهور مشكلة رفض السلطة وعدم الطاعة.

r. التعرف على الآثار المترنبة على مشكلة عدم الطاعة ورفض السلطة في العملية التعليمية

$$
\text { وظهر المشكلات الأسرية والمدرسية. }
$$

ع. التعرف على دور كلًا من المدرسة والآباء في مواجهة مشكلة عدم الطاعة ورفض السلطة.

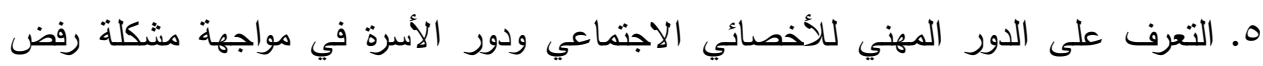
السلطة وعدم الطاعة.

\section{أهمية المهمه}

يمكن أن تحدد أهمية هذه المشكلة في عنصرين مهمين: • أهمية الظاهرة وهي رفض السلطة وعدم الطاعة الوالدية والمدرسية.

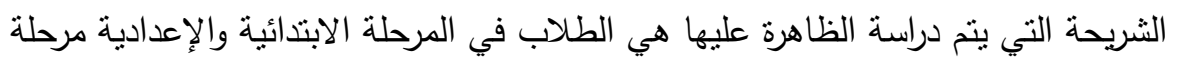

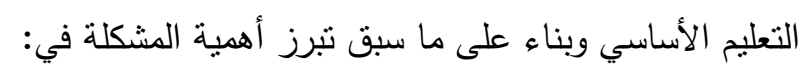
ا-1إن ظاهرة رفض السلطة وعدم الطاعة الوالدية والمدرسية لم تعد بالظاهرة الجديدة بل إنها لهاهي

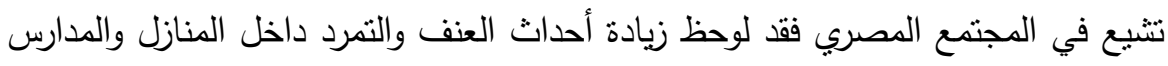
وأن بذلك أصبحت دراسة الظاهرة ضرورية لأن التمرد وعدم الطاعة ورفض السلطة يعيق لفيق عمليات التتمية المجتمعية. ץ- الثريحة التي تقوم بدراستها من أهم المراحل وهي المرحلة الابتدائية والإعدادية ولأن هذه

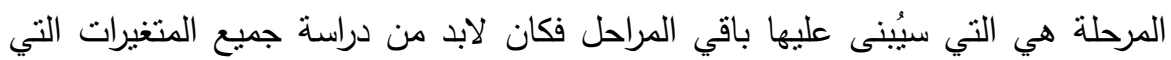

r-نرجع الأهمية لمرور الباحث بالمشكلة. 


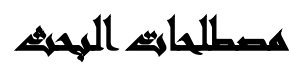

المتفيرات الاجتماعية: هي العوامل الاجتماعية السائدة في المجتمع كل عام له وظائفه

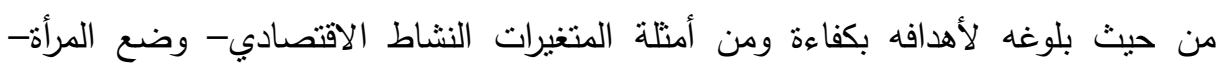
التعليم- العدالة الاجتماعية.

المتغيرات الفيزيقية: متغيرات فيزيقية داخلية بشقيها "الطبيعي والمشيد" وتشمل (الضوضاء- الإضاءة- التهوية والنوافذ- قاعات الأنشطة المدرسية- حالة الفصول العامةدورات المياه).

الطاعة: هي الامتثال والتوافق مع السلطة القائمة، يعني إطاعة المرؤوس للرئيس وتتفيذ أوامرهوعدم الخروج على القواعد والمعايير المتفق عليها. مفهوم القبول والرفض: رفض الطاعة الأسرية ورفض القواعد المدرسية يؤدي ذلك لكثير من المشكلات داخل المدرسة مثال (التأخر الدراسي - العنف المدرسي - العدوان) وأيضًا مشكلات الأسرة.

\section{القراسايت المايوية}

وفيما يلي عرض البحث في محورين نتاول فيهم متغيرات البحث وهم: (المتغير الفيزيقي -

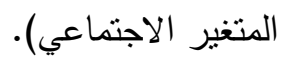
محور اهتم بالمتغير الاجتماعي:

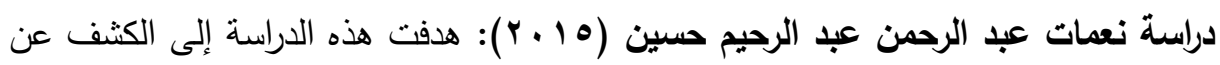

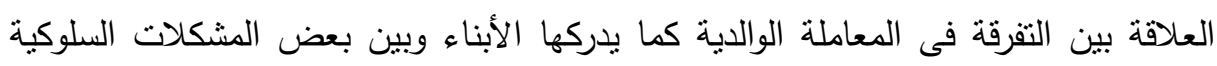

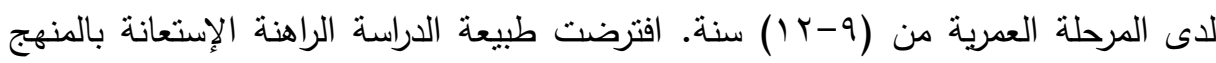

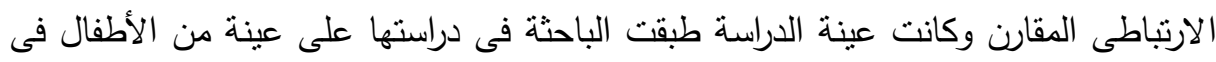

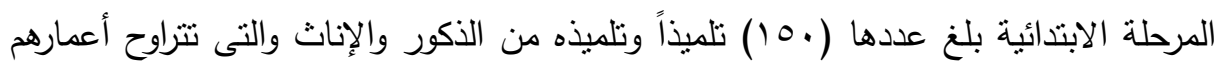
بين و-r ا سنوات. 
وتوصلت الدراسة إلى عدة نتائج أهمها: توجد علاقة ارتباطية دلالة إحصائية بين درجة التفرقة فى المعاملة الوالدية كما يدركهما الأبناء وبعض المشكهلات بوجلات السلوكية لديهم فى المرحلة

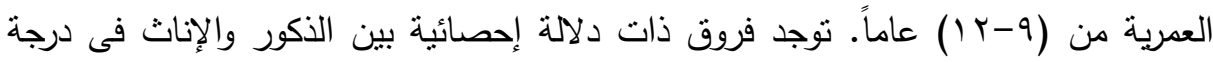

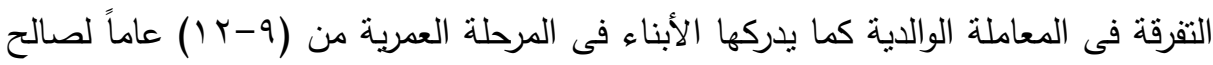
الذكور • توجد فروق ذات دلالة إحصائية بين الذكور والإناث فى درجة بعض المشه الشكلات

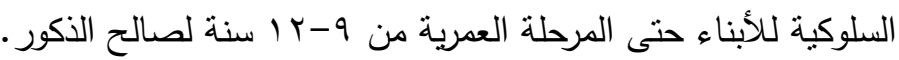

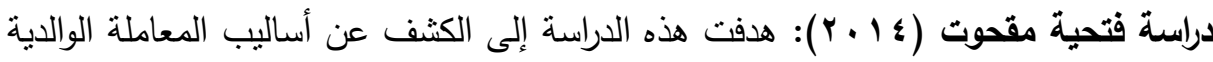

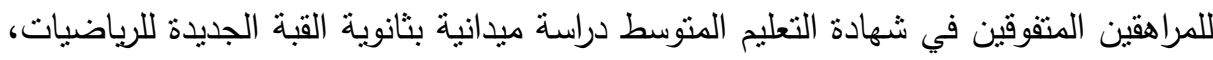
وكان عدد العينة التي طبقت عليها الدراسة (r T ( ) تلميذ وتلميذة وتم حصر العينة في التلاميذ

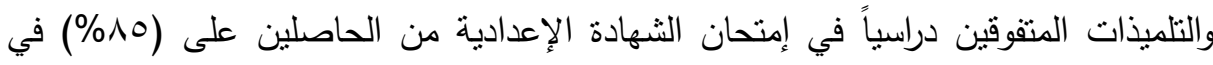
المجموع النهائي، واستخدت الباحثة الاسنبيان في جمع البيانات واستخدمت الباحثة المنهج الوصفي. وتوصلت النتائج إلى وجود علاقة ين التفوق الدراسي وتتجيع الأسرة للأبناء ومكافآته، كما نوجد علاقة بين معاملة الوالدين للأبناء بأسلوب ديمقراطي وبين تفوقهم الدراسي، ووجود علاقة بين التقوق الدراسي للأبناء وبين عدم التسامح معهم في حالة التقصير في أداء واجباتهم المدرسية وفي حالة التقصير أو حصولهم على درجات منخفضة في الامتحانات،

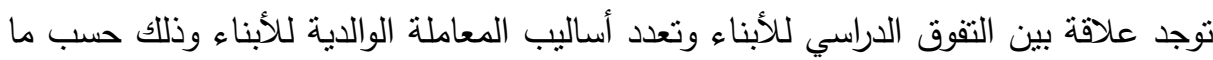
يقضيه الموقف من عقاب والبعد عن استخدام أسلوب واحد في التعامل مع الأبناء.

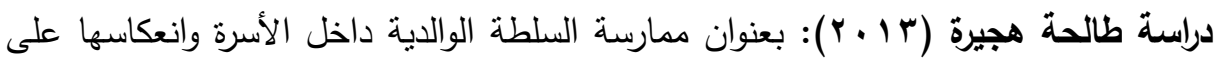
التوافق النفسي الاجتماعي للمراهقين، وهى دراسة ارتباطيه فرقية بين المراهقين الذكور والإناث الملحقين بالصف الثاني ثانوي. وذهبت إلي نتائج أن هناك علاقة ارتباطيه بين ممارسة الوالدية للسلطة المرنة والتوافق النفسي الاجتماعي للمراهق في الأسرة. وهناك علاقة ارتباطيه بين ممارسة الوالدين للسلطة المتتددة والتوافق النفسي الاجتماعي للمراهق في الأسرة.

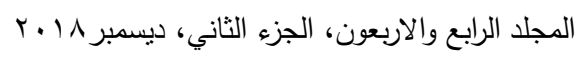




\section{محور اهتم بالمتغير الفيزيقي:}

دراسة أيمن محمود مميس عبد الله (10 بـ): أساليب المعاملة الوالدية كمنبئات بالأمن

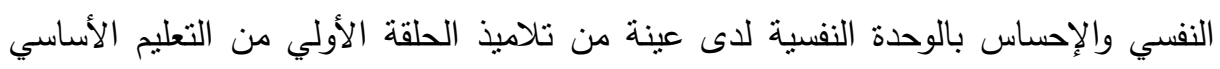

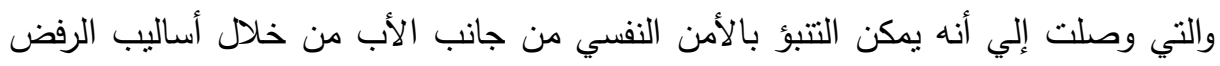

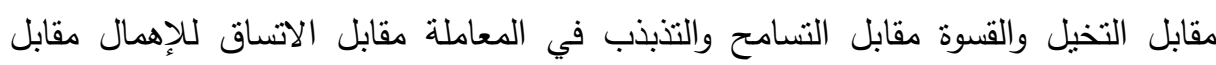

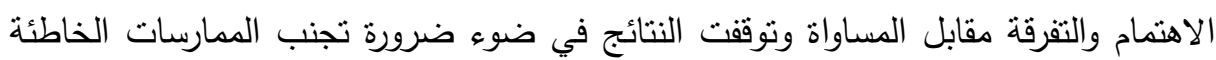

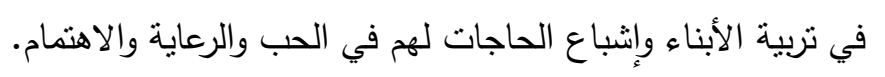

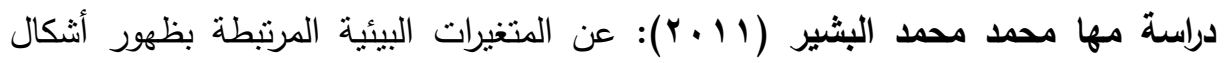

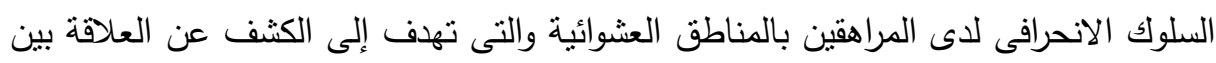

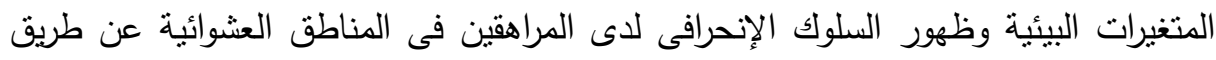

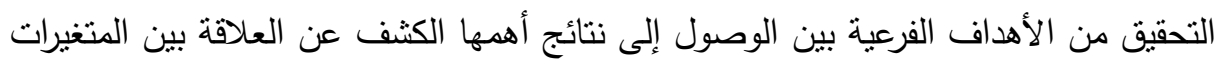

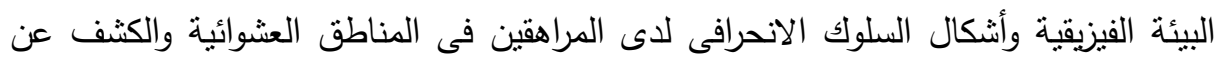

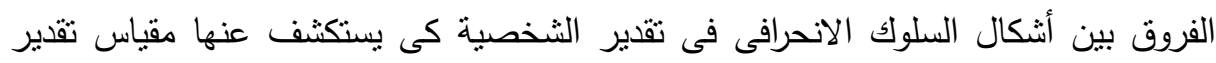

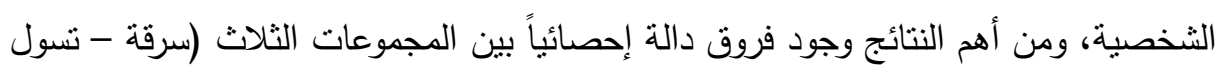

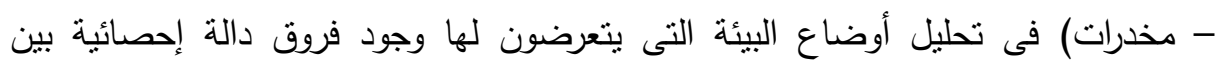

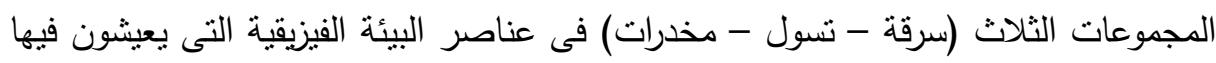
وجود فارق دالة إحصائياً بين المجموعات الثلاثة في البيئة الإجتماعية وبتباين تأثير البيئة البئة

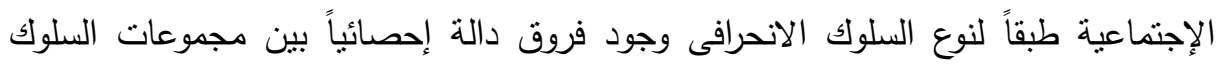

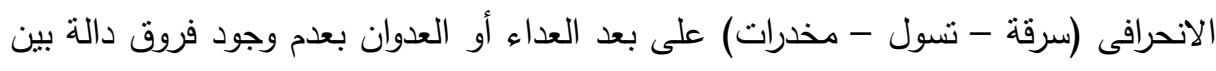

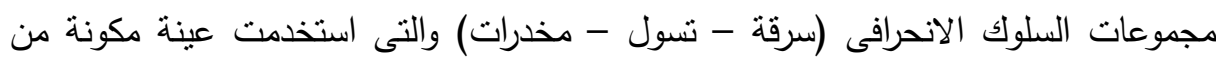

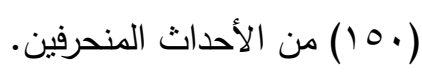

دراسة إيمان فوزى مصطفى (·1 (ب): أكدت الدراسة على العلاقة بين متغيرات البيئة

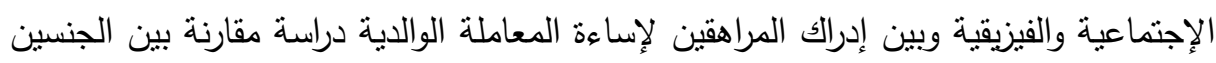

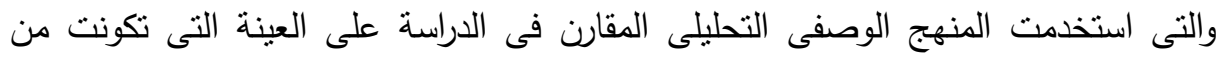
من r. . 
وذللك يوضح الأسباب حيث بمجرد معرفة هذه الأسباب تكون قد ساهمنا فى الحد من إساءة المعاملة الوالدية للمراهقين وساهمنا فى وجود مزج من التفاعل الإيجابي بين الآباء والأبناء

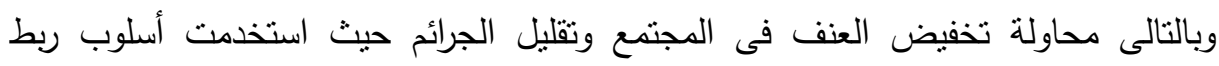
النتيجة بالسبب وأيضاً نوعية الأبناء بدور البيئة الهام فى إدراكهن للإساءة ودورها فى التأثنير عليهم بطبقة عامة فى كل جوانب الحياة.

\section{الإسار اللنظيه}

تتاولت دراسة المتغيرات الاجتماعية والمتغيرات الفيزيقية المرتبطة بمشكلة رفض السلطة

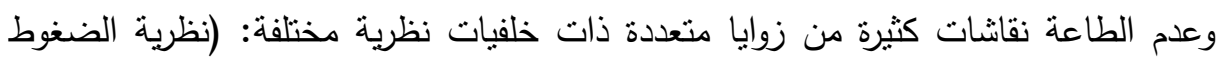

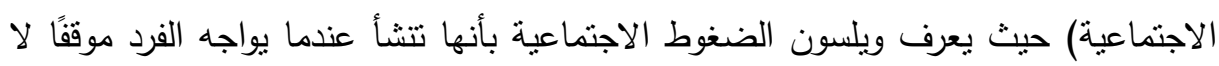
يسنطيع التكيف معه مما يؤدي لسلوك غير صحيح ينتج عنه نتائج سلبية.

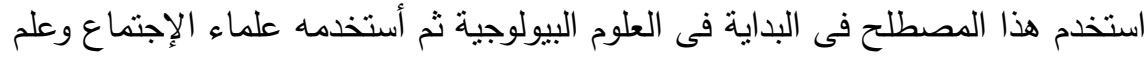
النفس فيعرف البريشت Albrecht الضغوط الإجتماعية بأنها الحالة التى تتجاوز فيها

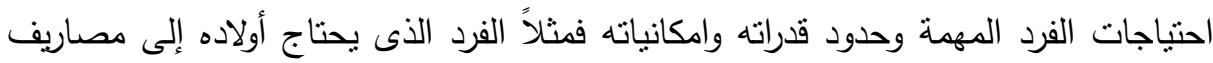
مدارس وعلاج.... الخ، وإمكانياته لا تسمح هذه الاحتياجات المهمة فإن هذا الموقف يمنل

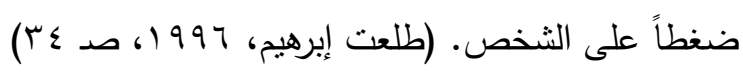

ويعرف ويلسون Willson الضغوط الإجتماعية بأنها تتشأ عندما يواجه الفرد موقفاً صعباً لا يستطيع التكيف معه. مدا يؤدى لسلوك غير صحيح ينتج عنه نتائج سلبيه. فمثلاً

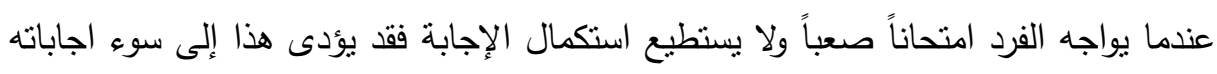

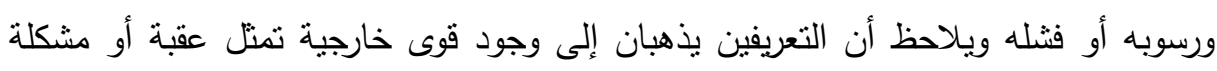

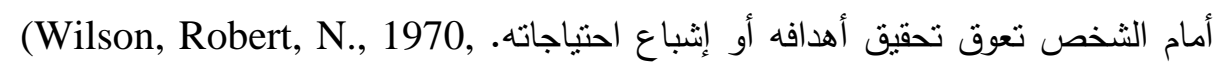

وفي هذا الصدد تشير نظرية النسق الايكولوجي إلى أن مفهوم النسق الأيكولوجي مفهوم

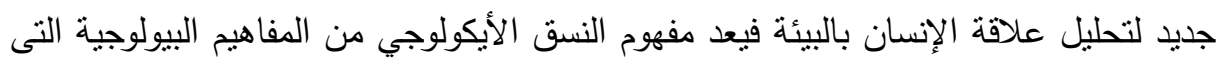

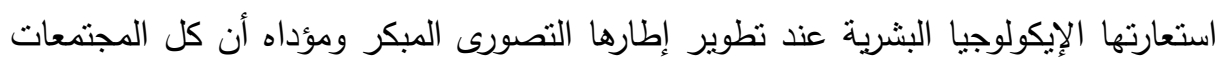

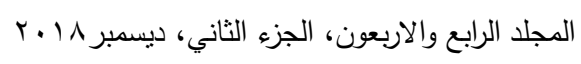


الطبيعية للكائنات الحية التى تعيش وتتفاعل بعضها البعض إرتباطاً وثيقاً بييئتها ومن ثم يبدو

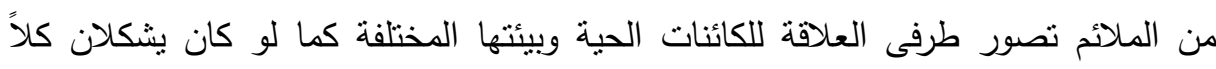
واحداً ومركباً وهو ما يشير إليه مفهوم النسق الإيكولوجي، ولقد ذهب تانسلى عالم البيولوجيا

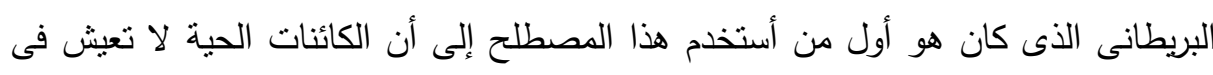

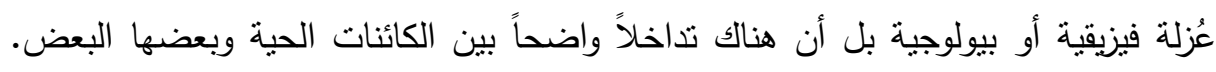

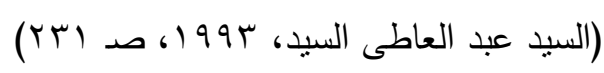

كما عرفت الأيكولوجية النسق الإيكولوجي مارجالف بأنه ذللك السياق الكلى الذى ينتج

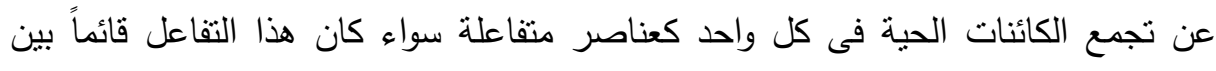

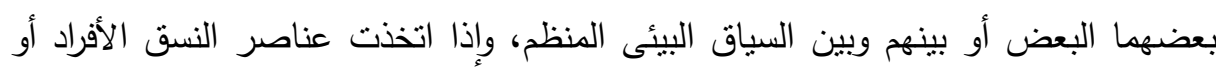

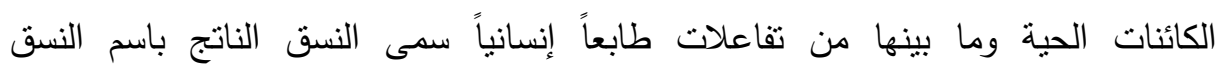

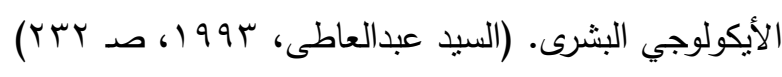
ومن وجهة نظر المناحي النظرية الأساسية في علم النفس البيئي وجد الباحثون في علم

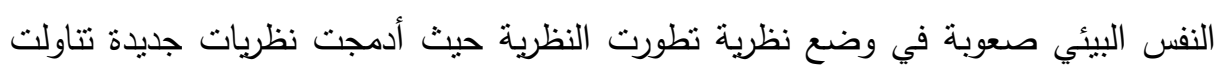

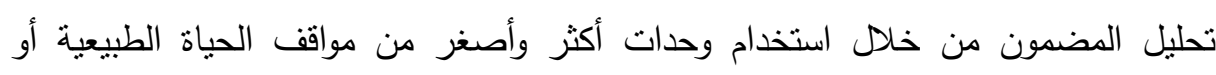
الخاصة. وأخرى قسمت مقياسًا مصغرًا أو تقربييًا للبيئات المختلفة حيث تم ربط الحقائق بالعلاقات

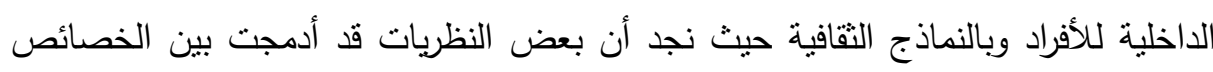

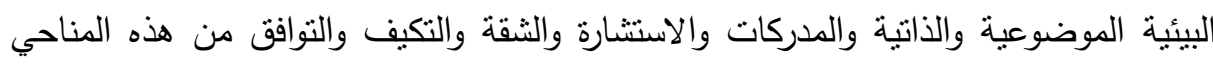
(منحى البيئي - منحى مستوى التكيف - منحى الحد في السلوك ونقيد القسر السلوكي).

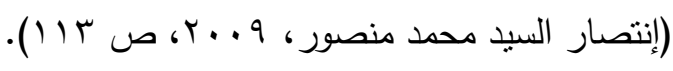

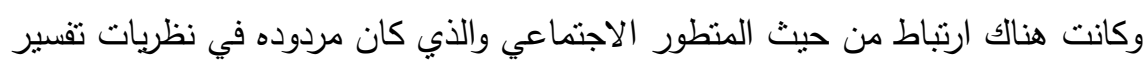

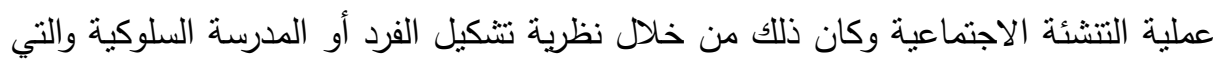

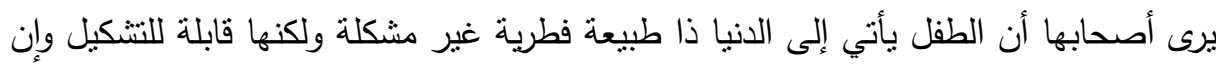
عملية النتشئة هي تشكل الطفل وأن الذي يقوم بالتشكيل الوالدان والمعلمون وغيرهم. (إنتصار

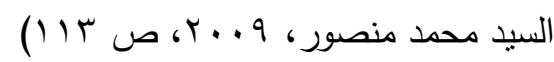




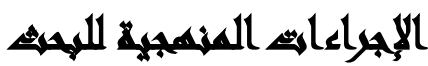

المنهج المستخدم: استخدم الباحثون في معالجة موضوع البحث منهج المسح الاجتماعي باستخدام العيشة مستقيدًا من معطيات المنهج الوصفي يرصد وتحليل أبعاد المتغيرين الاجتماعي والفيزيقي وأثرهم على ظهور مشكلة رفض السلطة وعدم الطاعة لدى عينة البحث. أداة البحث وتوصيفها: تم تصميم أدوات بحثية محددة وملائمة تتمنل أساسًا في استمارة الاستبيان التي تحتوي على مجموعة من الأسئلة والعبارات يجيب المبحوثون عنها وتدور حول محاور البحث الرئيسية الأربعة وبلغت عدد الأسئلة (VI) كما ورد بدليل المقابلة الاسم (اختياري) اسم المدرسة المرحلة التعليمية. ثبات وصدق أداة البحث: ثبات الأداة: اتضح من قيم معاملات الثبات لأبعاد النظام

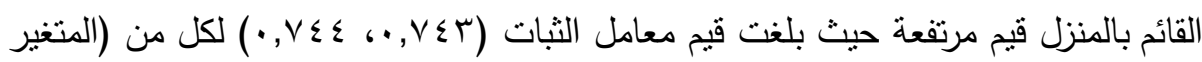

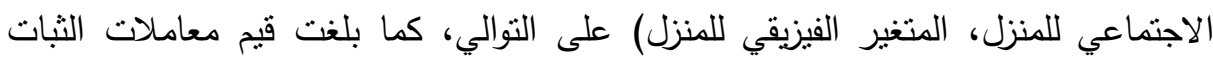

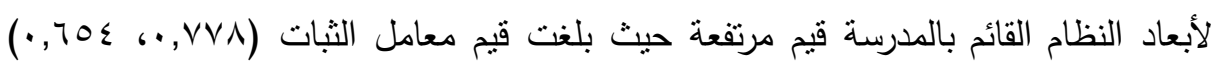

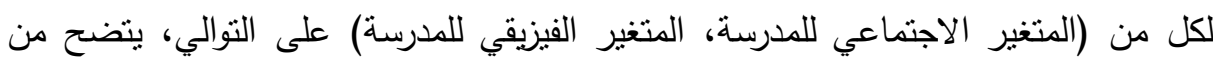

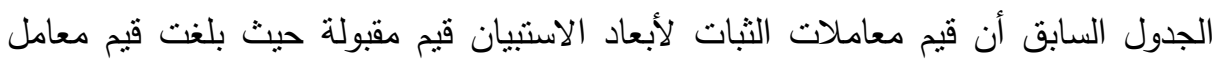

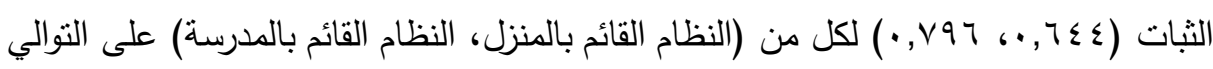

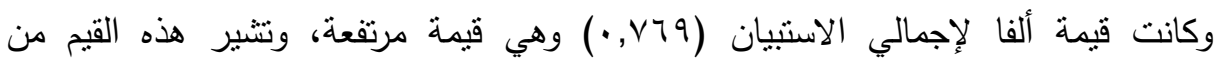
معاملات الثبات إلى صلاحية الاستبيان للنطبيق وإمكانية الاعتماد على نتائجه والوثثوق به. العينة وحجمها: تمثلت العينة في عينتين الأولى الطلاب بالمرحلة الابتدائية والصف الأول

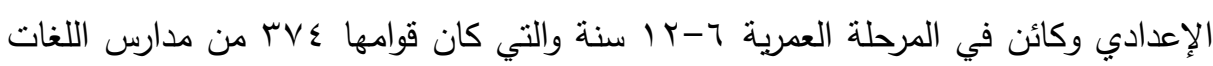
الرسمية لمنطقة النزهة- مدينة نصر وكانت منقسمة مناصفة بين الذكور والإناث. أما العينة الثانية من العينة كانت من الخبراء وهم . ب فرد من أساتذة الجامعة - أولياء الأمور -الأخصائيين الاجتماعيين والنفسيين بالمدرسة- المدرسين لهذه المرحلة. 
فترة ونطاق التطبيق الميداني: نم إجراء البحث الميداني في المدارس الرسمية للغات

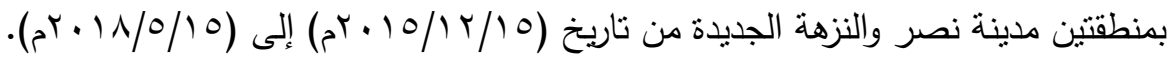

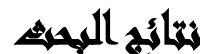

جلول (1): استجابة عينة الدراسة لعبارات المتغير الاجتماعي للمنزل تبعًا لمتغير النوع

\begin{tabular}{|c|c|c|c|c|c|c|c|c|c|c|c|c|c|c|}
\hline \multirow{3}{*}{ 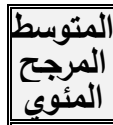 } & \multicolumn{6}{|c|}{ إناث } & \multirow{3}{*}{ |المترجيح| المئوي } & \multicolumn{6}{|c|}{ ذكور } & \multirow{3}{*}{ العبارات } \\
\hline & \multicolumn{2}{|c|}{ نعم } & \multicolumn{2}{|c|}{ أحيانا } & \multicolumn{2}{|l|}{$\bar{y}$} & & \multicolumn{2}{|c|}{ نعم } & \multicolumn{2}{|c|}{ احيانا } & \multicolumn{2}{|c|}{$\bar{y}$} & \\
\hline & $\%$ & | & $\%$ & ك & $\%$ & 5 & & $\%$ & 5 & $\%$ & जा & $\%$ & (5) & \\
\hline $00, r$ & $7 \cdot, 9$ & $V \cdot$ & rq,7 & T & 9,7 & 11 & $V \varepsilon, \varepsilon$ & $\neg \Lambda, \vee$ & Vq & $r \varepsilon, r$ & $\mathrm{rA}$ & V & $\wedge$ & سلوب التبعاضل فئ البيت \\
\hline 0 . & $V Y, Y$ & Ar & $1 \wedge, r$ & $|r|$ & 9,7 & 11 & $V \vee, 7$ & $V V, \Sigma$ & 19 & $11 \%, 9$ & 174 & $\Lambda, \vee$ & 1. & التعبير \\
\hline $71, r$ & $\varepsilon \varepsilon, r$ & 01 & $\varepsilon \varepsilon, r$ & 01 & $11, \pi$ & 11 & $7 \wedge$ & $7 \cdot, 9$ & V. & $r 7,1$ & $r \cdot$ & IT & 10 & هل التيت النقاش فهى فى \\
\hline $70, Y$ & $\varepsilon \varepsilon, r$ & 01 & $\leqslant \Lambda, V$ & 07 & V & $\wedge$ & $V Y$ & $7), V$ & VI & זr & rN & $0, r$ & 7 & هلتخذ الَّرارات هو من \\
\hline $79, r$ & $r r, 0$ & rv & $\pi, 0$ & Vr & $\mid 1,1$ & 10 & 0 . & TV & | & $0 \leq, \Lambda$ & $7 \pi$ & $1 \Lambda, r$ & $|r|$ & هلت \\
\hline $0 ., \Sigma$ & $v 1, r$ & $A Y$ & 19,1 & Tr & 9,7 & 11 & $\vee \varepsilon, \varepsilon$ & 79,7 & $\wedge$. & $Y Y, T$ & |rT| & $v, q$ & 9 & 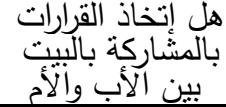 \\
\hline$\varepsilon \cdot, \wedge$ & $\mid \vee v, \varepsilon$ & r. & $r o, V$ & $\leqslant 1$ & $\sum 7,9$ & $0 \leqslant$ & $r v, r$ & $r Y, T$ & Tr & $r 0, v$ & $\leqslant 1$ & $\varepsilon 1, V$ & $\mid \leq \wedge$ & 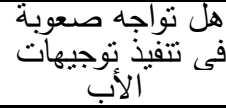 \\
\hline$\varepsilon \varepsilon, \varepsilon$ & $\pi$ & 10 & $\leqslant 1, V$ & $\mid \leqslant \wedge$ & $\leqslant 0, Y$ & Or & $r q, 7$ & $10, \mathrm{~V}$ & 11 & r & $\mathrm{rN}$ & 01,1 & 109 & فلى تتفيذّ توجيهاتِ صعوبة \\
\hline $0 \wedge$ & 7. & 79 & זוז & rی & V & $\wedge$ & $\Lambda \cdot, \Sigma$ & $v 7,0$ & $\wedge \wedge$ & $Y, V$ & ro & $1, V$ & $r$ & هل تقبلِ توجيه \\
\hline $0 \leqslant$ & $v r, q$ & 10 & $Y 1,1$ & ro & $\varepsilon, \Gamma$ & 0 & $\wedge \cdot, \wedge$ & $\vee \wedge, r$ & 9. & 19,1 & $r r \mid$ & $r, T$ & $r$ & هل تقبل توجيه \\
\hline 巾 & $r \wedge, \vee$ & |سץ| & rV & ו וץ & $\leq \varepsilon, \Gamma$ & 01 & $\varepsilon r, r$ & $r \cdot, \varepsilon$ & מ & r" & $\mathrm{rN}$ & ד, & $\leqslant Y$ & هل الأقبل توجياز \\
\hline
\end{tabular}


مجلة العلوم البيئية

معهد الدراسات والبحوث البيئة - جامعة عين شمس لهن لهن

تابع جدول ( ) : استجابة عينة الدراسة لعبارات المتغير الاجتماعي للمنزل تبعًا لمتغير النوع

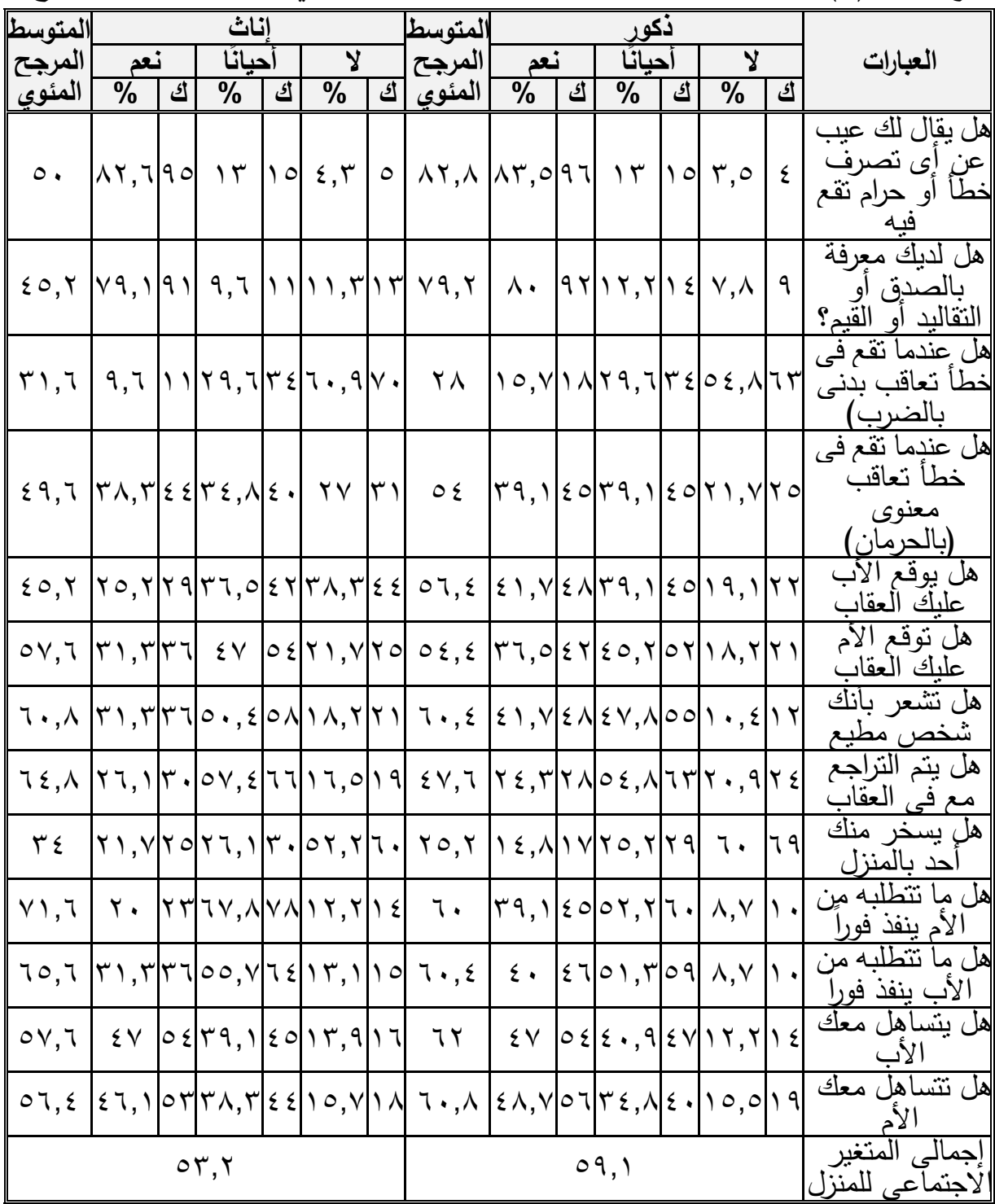


من الجدول السابق لوصف عبارات المتغير الاجتماعي للمنزل تبعاً لمتغير النوع نتوعت

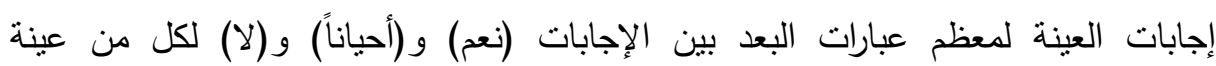

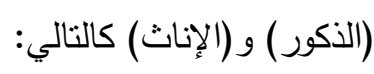

• كانت العبارة (هل يقال للك عيب عن أى تصرف خطأ أو حرام تقع فيه) أعلى موافقة حيث

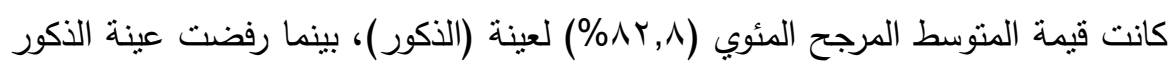
العبارة (هل تواجه صعوبة فى تتفيذ توجيهات الأب، هل نواجه صعوبة فى تتفيذ نوجيهات لتوبنه

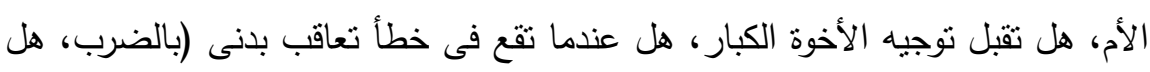

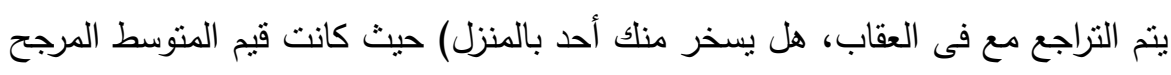

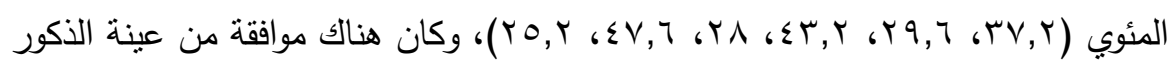

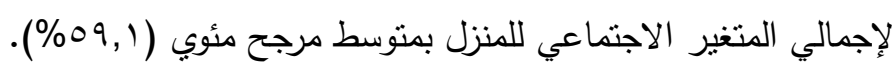

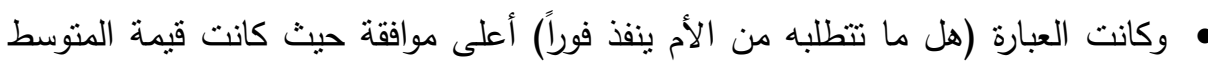

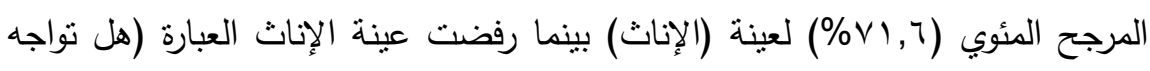

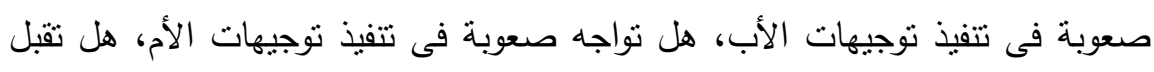

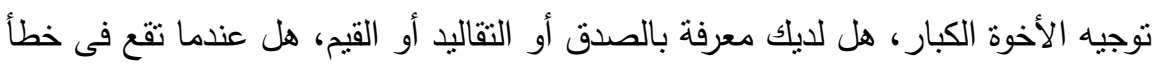

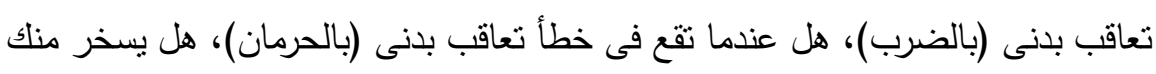

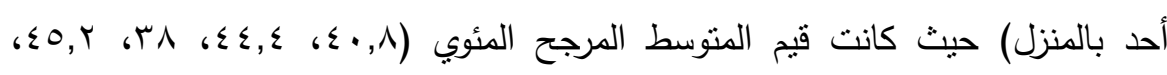

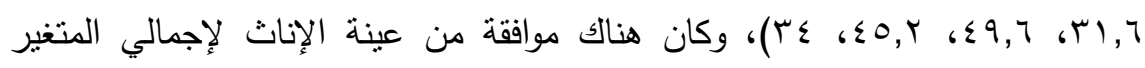

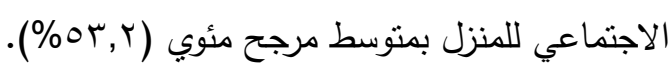

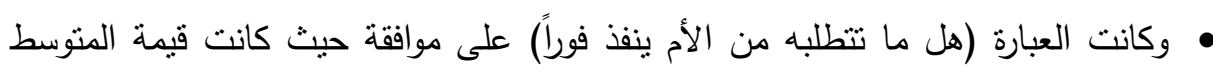

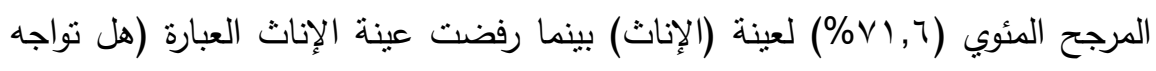
صعوبة فى تتفيذ نوجيهات الأب، هل تواجه صعوبة فى تتفيذ نوجيهات الأم، هل تقبل

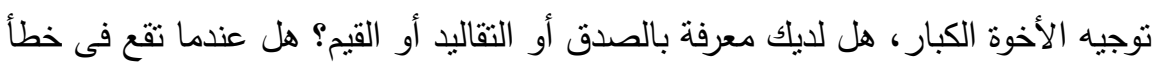

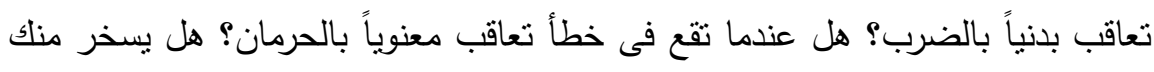

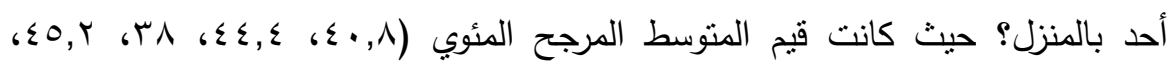




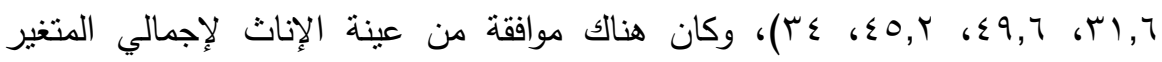

$$
\text { الاجتماعي للمنزل بمتوسط مرجح مئوي (r, (r. }
$$

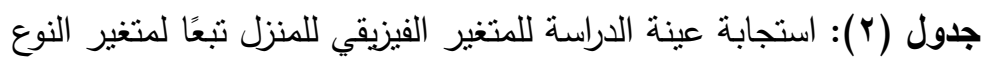

\begin{tabular}{|c|c|c|c|c|c|c|c|c|c|c|c|c|c|c|}
\hline \multirow{3}{*}{ المئوبح المئوي } & \multicolumn{6}{|c|}{ إناث } & \multirow{3}{*}{ المئوجيح } & \multicolumn{6}{|c|}{ ذكور } & \multirow{3}{*}{ العبارات } \\
\hline & \multicolumn{2}{|c|}{ نعم } & \multicolumn{2}{|c|}{ احيانا } & \multicolumn{2}{|l|}{$\bar{y}$} & & \multicolumn{2}{|c|}{ نعم } & \multicolumn{2}{|c|}{ احيانا } & \multicolumn{2}{|c|}{$y$} & \\
\hline & $\%$ & 5 & $\%$ & 5 & $\%$ & (5) & & $\%$ & 5 & $\%$ & 5 & $\%$ & (5 & \\
\hline$\varepsilon r, r$ & $7 \cdot, 9 \mid$ & $v$. & 17,0 & 19 & $r, T$ & ry & 70,7 & $7 \varepsilon, \Gamma$ & $V \varepsilon$ & $|17,9|$ & 17 & 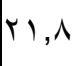 & ro & أدئي \\
\hline$\varepsilon r, \wedge$ & $r_{0, r}$ & rq & | & rq & $\varepsilon \cdot, 9$ & $\leqslant v$ & $\varepsilon q, r$ & $\varepsilon$. & $\leqslant 7$ & rV & | ו & (r, & rN & \\
\hline$\leq 0,7$ & $q r, r$ & 1.7 & $\Gamma, 0$ & $\varepsilon$ & $\varepsilon, \Gamma$ & 0 & $\Lambda Y, \Sigma$ & $\wedge 0, Y$ & 91 & $\Lambda, \vee$ & 1. & 7 & $\mathrm{~V}$ & \\
\hline 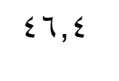 & $90, v \mid$ & 11. & $r, T$ & $r$ & $1, V$ & $r$ & $\wedge \uparrow, \varepsilon$ & 94 & $1 \cdot V$ & $1, V$ & $Y$ & $0, r$ & 7 & \\
\hline$r q, 7$ & 09,1 & 71 & $r, \tau$ & $r$ & ץ & $\varepsilon \varepsilon$ & $7 \varepsilon, \varepsilon$ & $\pi v, \lambda$ & $\mathrm{VA}$ & $\varepsilon, r$ & 0 & $r v, \Lambda$ & |r & حجرة \\
\hline$\varepsilon q, r$ & $\lambda r, T$ & 90 & $\mid Y, Y$ & $1 \varepsilon$ & $0, Y$ & 7 & $\vee \wedge, 乏$ & $|\lambda \cdot, 9|$ & 94 & $\Lambda, \vee$ & 1. & 9,5 & $|Y|$ & زلز الشمس \\
\hline$\varepsilon \varepsilon, \wedge$ & $\Lambda V$ & $1 \ldots$ & $0, Y$ & 7 & $\vee, \Lambda$ & 9 & $\vee 9,7$ & $\lambda r, 0$ & 97 & 7,1 & $\mathrm{~V}$ & $1 \cdot, \varepsilon$ & $|Y|$ & 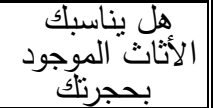 \\
\hline$\leqslant 7, \wedge$ & $91, \pi \mid$ & 1.0 & $0, Y$ & 7 & $r, 0$ & $\varepsilon$ & $\Lambda 0, r$ & $\wedge 9,7$ & $1 . r$ & 7,1 & $\mathrm{v}$ & $\varepsilon, \Gamma$ & 0 & |هل تصلياه النظيفزة للكئ \\
\hline$\varepsilon q, r$ & $\wedge 7,1$ & 99 & $1 \cdot, \varepsilon$ & $1 Y$ & $r, 0$ & $\varepsilon$ & $\Lambda \varepsilon$ & $\wedge 7,1$ & 99 & $1 \cdot, \varepsilon \mid$ & $1 Y$ & $\Gamma, \varepsilon$ & $\varepsilon$ & |هل تشعر منزلكالرضا \\
\hline & & $\varepsilon \varepsilon$, & & & & & & & 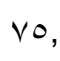 & & & & & أجماً أفيزا \\
\hline
\end{tabular}

من الجدول السابق لوصف عبارات المتغير الفيزيقي للمنزل تبعاً لمتغير النوع تتوعت

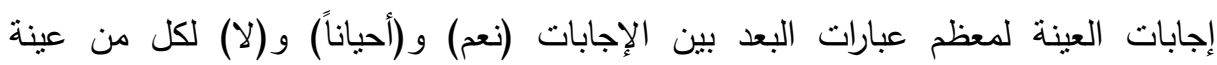

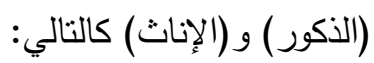

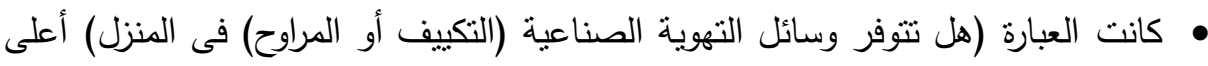

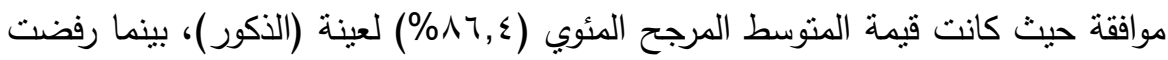

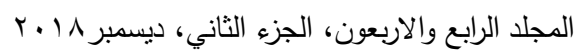


عينة الذكور العبارة (هل تتعر بالأدخنة أو الأتربة فى الهواء المحيط بك) حيث كانت قيم

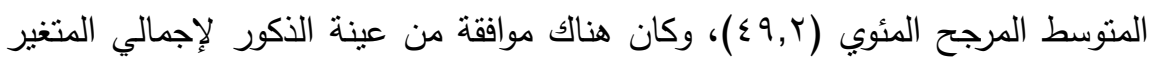

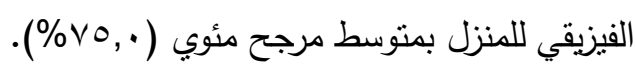

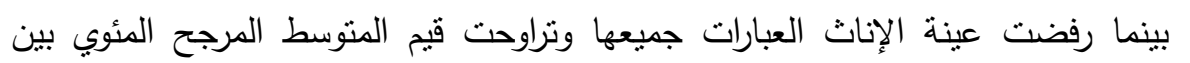

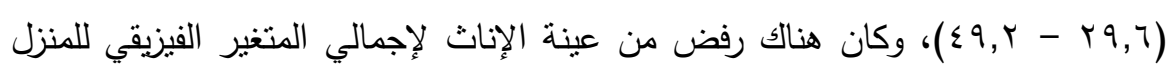

$$
\begin{aligned}
& \text { بمتوسط مرجح مئوي (r, ror\%). } \\
& \text { النظام القائم بالمدرسة: }
\end{aligned}
$$

\begin{tabular}{|c|c|c|c|c|c|c|c|c|c|c|c|c|c|c|}
\hline \multirow{3}{*}{ 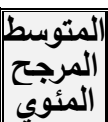 } & \multicolumn{6}{|c|}{ إناث } & \multirow{3}{*}{ |المتوسط |لمرجي |لمئوي } & \multicolumn{6}{|c|}{ ذكور } & \\
\hline & \multicolumn{2}{|c|}{ نعم } & \multicolumn{2}{|c|}{ احيانا } & \multicolumn{2}{|l|}{$\bar{y}$} & & \multicolumn{2}{|c|}{ نعم } & \multicolumn{2}{|c|}{ احيانًا } & \multicolumn{2}{|c|}{$\bar{y}$} & \\
\hline & $\%$ & 5 & $\%$ & פ & $\%$ & 5) & & $\%$ & 5 & $\%$ & 5 & $\%$ & (5) & \\
\hline ऍ & 19,1 & Yr & r r, & rv & $\varepsilon \wedge, \vee$ & 07 & r, & 19,1 & rr & سץ & אן & $\leqslant V, q$ & 00 & \\
\hline & Tr, & דין & ه, & $\leqslant 1$ & $\leqslant 1, V$ & $\leqslant \wedge$ & ع, & r. & rr| & ع, • ب & هץ & $\leqslant q, 7$ & $0 \mathrm{~V}$ & \\
\hline To,7 & rv, & $\leqslant \mu$ & r. & |r & $\leqslant Y\rceil$, & $\leqslant 9$ & $\varepsilon \varepsilon, \wedge$ & ه , & $\leqslant 1$ & $r 7,1$ & r & r & $\leqslant \varepsilon$ & أنشطة \\
\hline 0 . & ه & $\leqslant 1$ & | & $\leqslant Y$ & $r v, \Lambda$ & |r & 09,7 & $\varepsilon \wedge, V$ & 07 & $r, r$ & קس & 19,1 & Yr & مـ \\
\hline$r, \varepsilon$ & 9,7 & 11 & $1 \mathrm{~V}, \varepsilon$ & r. & r & A $\varepsilon$ & $r V, r$ & $10, \mathrm{~V}$ & 11 & $r v, \Lambda$ & זr| & 07,0 & 70 & \\
\hline 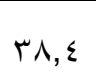 & r, ו & דץ & $r 7,1$ & • & $\varepsilon Y, 7$ & $\leqslant 9$ & $\varepsilon 0, Y$ & r, & rq & r. & סץן & o, & $\leqslant 1$ & مأب \\
\hline$r \varepsilon, \varepsilon$ & r. & אי & 17,0 & 19 & $7 \pi, 0$ & VT & r, & rV & | & $1 \leqslant, \wedge$ & 18 & $0 \wedge, r$ & $7 V$ & دالنّير المدرسة للئة \\
\hline r & ov, s & 77 & 7,1 & V & רו, & $\varepsilon Y$ & 01,7 & or & 71 & 7,1 & V & $\varepsilon \cdot, q$ & $\varepsilon V$ & هل تعرف الاخصائح \\
\hline$r \eta, \wedge$ & $\varepsilon \varepsilon, r$ & 01 & V & $\Lambda$ & $\varepsilon \wedge, V$ & 07 & $\varepsilon V, 7$ & $\varepsilon V, \Lambda$ & 00 & $\mathrm{~V}, \Lambda$ & 9 & $\varepsilon \varepsilon, \Gamma$ & 01 & هل تعرف عمله \\
\hline r & r & סץ & 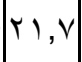 & ro & $\leqslant \vee, \Lambda$ & 00 & r & س & r人 & 19,1 & trt & $\varepsilon V, \wedge$ & 00 & \\
\hline r & $\varepsilon$. & $\leqslant 7$ & $1 \varepsilon, \wedge$ & $1 \mathrm{~V}$ & $\leqslant 0, r$ & $0 Y$ & $\varepsilon r$ & $r v, \varepsilon$ & $\leqslant r$ & 17,0 & 19 & $\leqslant 7,1$ & OM & \\
\hline$r \varepsilon, \wedge$ & $10, \mathrm{~V}$ & 11 & 19,1 & rr| & $70, r$ & vo & r & $|r 7,1|$ & • & Y I, V & ro & $O r, Y$ & $7 \cdot$ & \\
\hline$\varepsilon r, \wedge$ & ס, & tr & r & $\varepsilon \cdot$ & $\varepsilon 1, \wedge$ & $\leqslant \wedge$ & $\varepsilon 1, r$ & r ו ו ו & |דין & rV & ו & $\varepsilon 1, \wedge$ & $\leqslant \lambda$ & \\
\hline
\end{tabular}

جدول (ץ): استجابة عينة الدراسة المتغير الاجتماعي للمدرسة تبعًا لمتغير النوع 
مجلة العلوم البيئية

معهد الدراسات والبحوث البيئية - جامعة عين شمس له

\begin{tabular}{|c|c|c|c|c|c|c|c|c|c|c|c|c|c|c|}
\hline \multirow{3}{*}{ المئوبح المبحي } & \multicolumn{6}{|c|}{ إناث } & \multirow{3}{*}{$\mid$} & \multicolumn{6}{|c|}{ ذكور } & \\
\hline & \multicolumn{2}{|l|}{ نعم } & \multicolumn{2}{|c|}{ أحيانا } & \multicolumn{2}{|l|}{$y$} & & \multicolumn{2}{|c|}{ نعم } & \multicolumn{2}{|c|}{ آحيانا } & \multicolumn{2}{|c|}{$y$} & \\
\hline & $\%$ & |5 & $\%$ & S & $\%$ & S & & $\%$ & | & $\%$ & 5 & $\%$ & 5 & \\
\hline " & $r 0, v$ & $\leqslant 1$ & $r \cdot, q$ & $r \leq \mid$ & $r \wedge, r$ & 0. & $\varepsilon \cdot, \wedge$ & $r 0, v$ & $\leqslant 1$ & $\mid V, r$ & $r$. & $\varepsilon V$ & $0 \leqslant$ & |هل أنت راضي عن أداء \\
\hline rᄉ & $r 0, v$ & $\leqslant 1$ & rr,o & rv & $\varepsilon \cdot, \lambda$ & $\leqslant V$ & $07, \wedge$ & $\leqslant \vee, \lambda$ & 00 & $r v, \lambda$ & 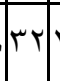 & r & rN & هشكلاتلك بالمدرسة الآب في \\
\hline$\varepsilon \cdot, \varepsilon$ & $\leqslant 9,7$ & $0 v$ & 19,1 & $|r r|$ & $r, r \mid$ & דr| & 01 & $\leqslant \wedge, \vee$ & 07 & $r \wedge, \vee$ & |r|r| & $r, T$ & rt & هش تشاتلك بالمدرسة الآم في \\
\hline of & $r 0, v$ & $\leqslant 1$ & $\varepsilon \cdot, q$ & $\leqslant V$ & $r r, \varepsilon$ & TV & $O V, Y$ & $\varepsilon r, T$ & $\leqslant 9$ & $r q, 1$ & $\leq 0$ & $1 \wedge, r$ & $\mid r_{1}$ & بتوجيكاك فيع من المدرسة \\
\hline$\leqslant 7, \varepsilon$ & $r \varepsilon, \lambda$ & $\varepsilon \cdot$ & זr & rN| & $r r, r$ & rv & or & $\varepsilon$. & $\leqslant 7$ & זT & rN & rV & ו ו & |هل مدرسك يقيم بينك حورار \\
\hline$\varepsilon \wedge, \wedge$ & $r \varepsilon \varepsilon, r$ & rN & $\varepsilon \cdot, 9$ & $\leqslant V$ & $r \leq, \lambda$ & $\leqslant$. & $\varepsilon \wedge$ & $r q, 1$ & $\leqslant 0$ & $r 7,1$ & $r . r$ & $r \varepsilon, \wedge$ & $\varepsilon$. & |دلب يتعامل مدرسك (التشحيح) \\
\hline$\varepsilon \varepsilon, \varepsilon$ & TV & | & $r \varepsilon, \wedge$ & $\leqslant$. & rی, r| & $\leqslant \varepsilon$ & $0 \cdot, \wedge$ & $\varepsilon \cdot, q$ & $\leqslant v$ & $r \wedge, v \mid$ & |r|r| & r & ro & هل بلإًاً إلى تقوجيه \\
\hline $01, Y$ & r7,0 & $\mid \leqslant Y$ & $r v, \varepsilon$ & $\leqslant \mu$ & $r 7,1$ & r. & $0 \leq, \wedge$ & $r q, 1$ & $\leqslant 0$ & $\varepsilon \cdot, q$ & $\leqslant V$ & r. & rr & هل يقوم الحوار بينك المدرس بهدوء \\
\hline$\varepsilon r, \tau$ & $\varepsilon \cdot, q$ & $\leqslant \vee$ & TV & $\mid$ & $r, r \mid$ & rv & 01,7 & $\varepsilon \cdot, q$ & $\leqslant V$ & $r \cdot, \Sigma \mid$ & rol & $r \wedge, \vee$ & W & هل التث ترتدى زئ بالطريقة \\
\hline $00, Y$ & $r \leqslant, r$ & rN & $\leqslant \vee, \wedge$ & 00 & $r v, \lambda$ & ו & $0 ., \varepsilon$ & r & rat & $\varepsilon V$ & $0 \leqslant 1$ & Y,$\Lambda$ & ro & |لمدرستة ولا تخالفها قواعد \\
\hline$\varepsilon \wedge$ & r & |רץ & | & $\leqslant Y$ & $r r, 1$ & rv & $\varepsilon V, r$ & $r \wedge, r$ & $\leqslant \leqslant$ & $r 7,1$ & $r$. & ro,v & $\mid \leqslant 1$ & هل تحضر الطابور \\
\hline$\varepsilon \varepsilon, \wedge$ & r & $\leqslant Y$ & $\mu \cdot, \Sigma$ & ro & Tr & N & $0 \leqslant$ & $\varepsilon$. & $\leqslant 7$ & $r v, \Sigma$ & $\leqslant \mu$ & $r, T$ & rT & |هل تنتظم فى الحضور يوم \\
\hline$\Gamma \wedge, \wedge$ & $r$. & rM| & $r r, r \mid$ & rv & $\leqslant \vee, \lambda$ & 00 & Tะ & $r r, T \mid$ & ry & $r \wedge, \vee$ & |r|r| & $\varepsilon \wedge, \vee$ & 07 & |أصدقهائك مشاكل مع \\
\hline rs & |r, q & rq & $r$. & r & $\leq 7,1$ & or & $\varepsilon \cdot, \wedge$ & $\mu_{\cdot}, \varepsilon \mid$ & rop & $r v, \lambda$ & r & $\leqslant 1, V$ & $\mid \leqslant 1$ & هل اللك مشاكل مع \\
\hline ru,z & $\wedge \wedge, \Gamma$ & Y 1 & $r \cdot, \Sigma$ & ro & $01, \Gamma$ & 109 & $r 0, r$ & $r \leqslant, r \mid$ & $r N \mid$ & $r v, \lambda$ & |r & $\leqslant \vee, q$ & 100 & أسلوب أنت التعامل فلى عن \\
\hline & & rq & १, $₹$ & & & & & & & , & & & & الأجنماعي اللمدير المدرة \\
\hline
\end{tabular}




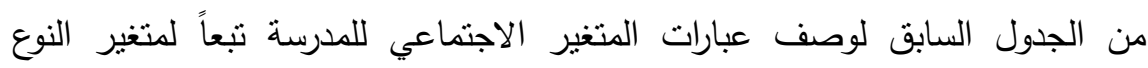

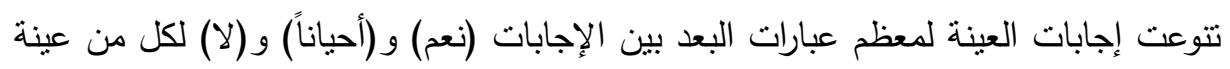

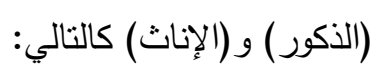

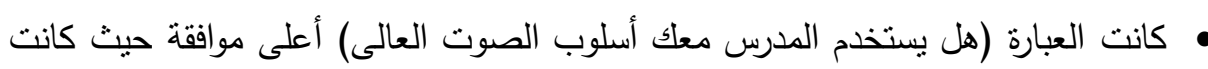

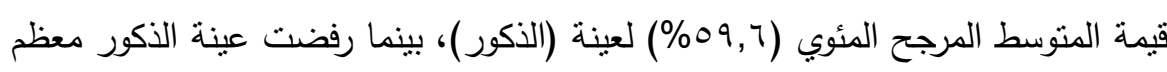

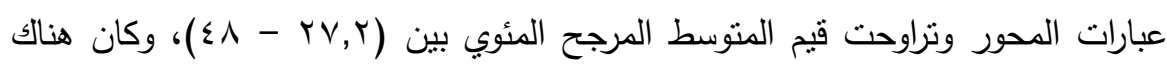

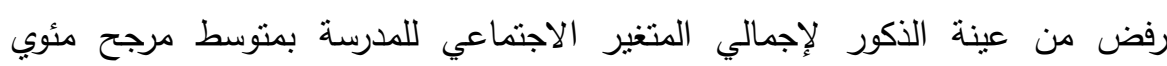

$$
\text { . }(\% £ 0, \cdot r)
$$

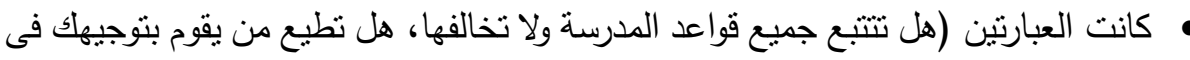

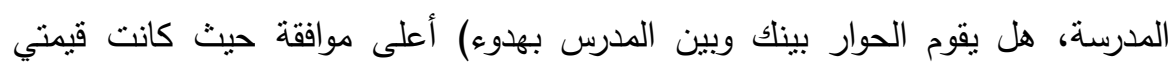

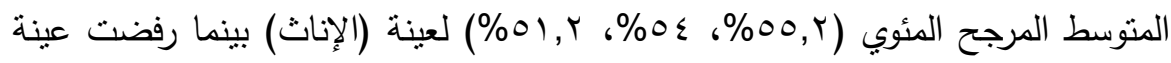

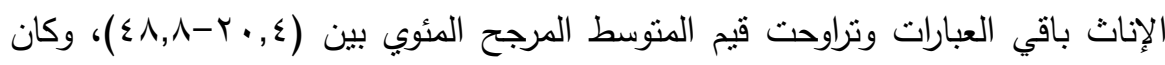
هناك رفض من عينة الإناث لإجمالي الدتغير الفزيقي للمدرسة بمنتوسط مرجح مئوي

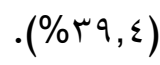


مجلة العلوم البيئية

معهد الدراسات والبحوث البيئية - جامعة عين شمس لئس

جدول (ء):استجابة عينة الدراسة المتغير الفيزيقي للمدرسة تبعًا لمتغير النوع

\begin{tabular}{|c|c|c|c|c|c|c|c|c|c|c|c|c|c|c|}
\hline \multirow{3}{*}{ 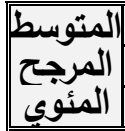 } & \multicolumn{6}{|c|}{ إناثاث } & \multirow{3}{*}{$\mid$} & \multicolumn{6}{|c|}{ ذكور } & \multirow{3}{*}{ العبارات } \\
\hline & \multicolumn{2}{|c|}{ نعم } & \multicolumn{2}{|c|}{ أحيانا } & \multicolumn{2}{|l|}{$\bar{y}$} & & \multicolumn{2}{|c|}{ نعم } & \multicolumn{2}{|c|}{ الحيانا } & \multicolumn{2}{|l|}{$\bar{y}$} & \\
\hline & $\%$ & \begin{tabular}{|l|}
5 \\
\end{tabular} & $\%$ & ك) & $\%$ & 5 & & $\%$ & St & $\%$ & 5) & $\%$ & 5) & \\
\hline רץ & $0 r, r$ & 7. & 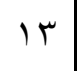 & 10 & $r \varepsilon, \lambda$ & $\varepsilon$ & 00,7 & $0 \cdot, \varepsilon \mid$ & 01 & $r$. & سזr| & $r q, 7$ & | $\mid$ & |الإم \\
\hline rq & r , & ro & 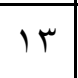 & 10 & $07,0 \mid$ & 70 & $\Gamma \cdot, \wedge$ & $r r, 0 \mid$ & rV & $r$. & |rT| & 07,0 & 70 & ثاث \\
\hline r & $\uparrow \wedge, \uparrow$ & $\leqslant \leqslant$ & $1 \leq, \wedge$ & $1 \mathrm{~V}$ & $\varepsilon V$ & $0 \leqslant$ & $r 0,7$ & $r v, \Lambda$ & r & $r i, V \mid$ & ro & $0 \cdot, \varepsilon$ & 01 & هوبة \\
\hline$\Gamma \varepsilon, \xi$ & $\leqslant \wedge, \vee$ & 07 & $\pi$ & 10 & r^, r & $\leqslant \varepsilon$ & $\varepsilon \wedge$ & $\leqslant 7,1$ & or & $\mid r, Y$ & $1 \leqslant$ & $\leqslant 1, \mathrm{~V}$ & $1 \leq \lambda$ & مناسب \\
\hline r r & 19,1 & r r & 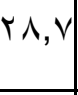 & سب & $O r, Y$ & 7. & ro, 7 & $r 7,1$ & . ". & $r 0, Y$ & rq & $\leqslant \wedge, \vee$ & 107 & بكل \\
\hline $1 \mathrm{I}, \Lambda$ & $\wedge, \vee$ & 1. & 9,7 & 11 & $\lambda \perp, V$ & $9 \leq$ & $1 Y, \varepsilon$ & 9,7 & 11 & $\vee, \Lambda$ & 9 & $\lambda r, T$ & 90 & نة فورات \\
\hline $10, r$ & 19,1 & YY & V & $\Lambda$ & $V r, q$ & 1 0 & TY & 17,0 & 19 & $1 \leqslant, \wedge$ & $1 \mathrm{~V}$ & $\neg \wedge, \vee$ & $1 \vee 9$ & \\
\hline r & $0 Y, Y \mid$ & 7. & $\vee, \wedge$ & 9 & $\varepsilon$. & $\leqslant 7$ & $0 \leqslant, \leqslant$ & $O r, Y$ & 7. & $1 T, q$ & 17 & $r r, q$ & | & هل فناء المدرسة \\
\hline$r Y, \varepsilon$ & $|r, 0|$ & $\leqslant Y$ & 7,1 & $\mathrm{~V}$ & $0 V, \Sigma$ & 77 & r. & rV & |וr| & $11, \pi$ & $1 T$ & $71, \mathrm{~V} \mid$ & VI & في مكان مزدة نقم \\
\hline rı,人 & 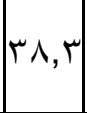 & $\leqslant \leqslant \mid$ & $r \cdot, q$ & $r \varepsilon$ & $\varepsilon \cdot, 9$ & $\leqslant V$ & $\varepsilon r, \wedge$ & $r q, 1$ & $\leqslant 0$ & $1 \leqslant, \wedge$ & $1 \mathrm{~V}$ & $\leqslant 7,1$ & 04 & هل المداطةٍ \\
\hline & & rA &, 1 & & & & & & & $7, V$ & & & & للمدرستة \\
\hline
\end{tabular}

من الجدول السابق لوصف عبارات المتغير الفيزيقي للمدرسة تبعاً لمتغير النوع تتوعت

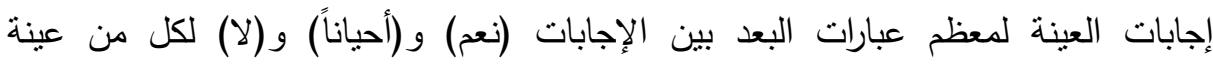

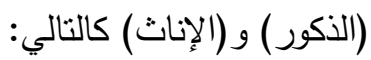
كانت العبارتين (هل تتوفر الإضاءة الجيدة فى الفصل، هل فناء المدرسة مناسب) أعلى

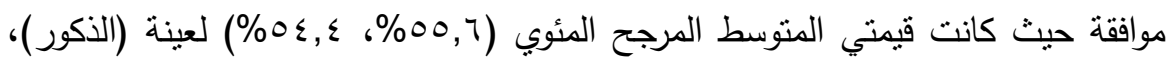
بينما رفضت عينة الذكور باقي العبارات وتراوحت قيم المتوسط المرجح المئوي بين 
(

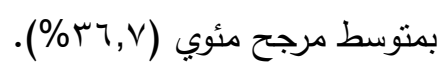

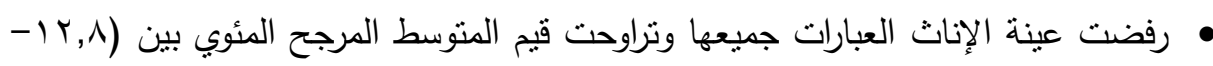

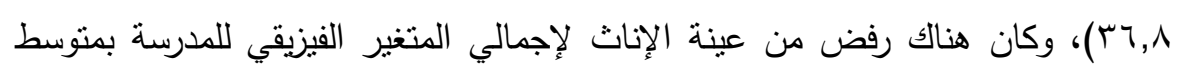

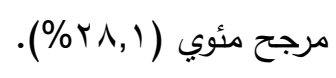

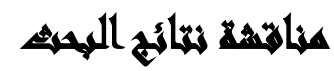

في ضوء الأسئلة التي طرحها الباحثون والدراسات السابقة والمرجعية، وما انتهى إليه من نتائج يمكن مناقتشتها في المحاور الآتية: التساؤل الأول: ما هي الأسباب التي أدت إلى ظهور مشكلة عدم الطاعة ورفض السلطة فئن

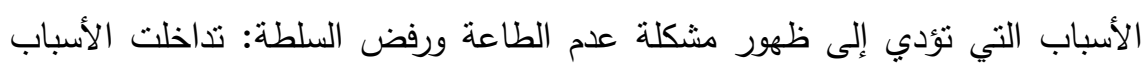

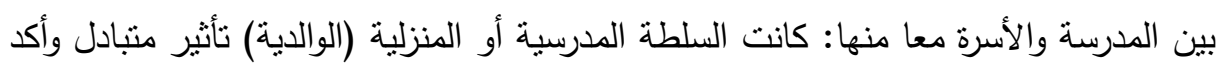

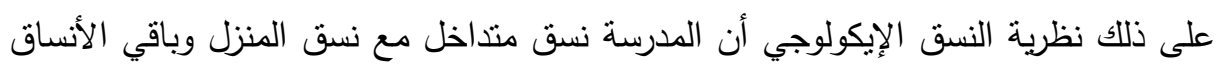

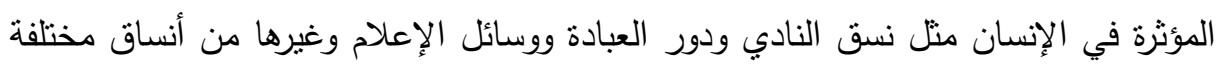
وأيضا جاءت الأسباب مؤكدة أن التتشئة الإجتماعية أن لها أكبر الأثر في تكوين الطيان الطفل بوسائلها السليمة وغير السليمة وتكوين شخصية الطفل فكان من وسائل التشئئة الإجتماعية

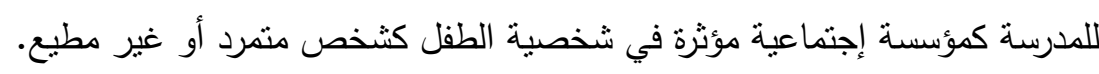
التساؤل الثاني: ما هي الأسباب التي تؤدي إلى عدم الطاعة ورفض السلطة؟ يأتي فثل الوالدين ودور الدين ووسائل الإعلام المختلف في وضوح الألئي الأمور الدينية للأطفال مما يجعلهم لا يدركون ما هو دورهم وما هو واجبهم نحو الآباء ونحو من هو أكبر ودير منهم وهذا التقصير يؤثر كثيرا في ظهور العديد من المشاكل وليس مشكلة رفض السلطة وعدم دهاه الطاعة فقط.

التساؤل الثالث: ما هو مفهوم السلطة في المدرسة؟ جاءت النتائج كلها على أن السلطة هي أداة فوق الطالب أي أداة لتقويمه وتعديل سلوكه

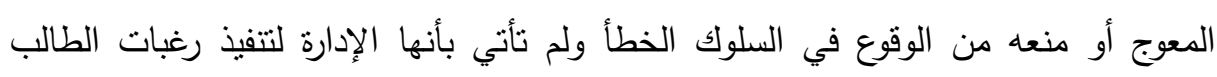


وإثباعها بالطرق التربوية السليمة جاءت كأداة للثثاب والعقاب ووضع القوانين المقيدة لذلك، المدرس اتخاذ القرار الناجح وهذا يأتي من خلال السلطة الديكتانورية وليست الديمقراطية لأن الديمقراطية تؤدي إلى تعطيل القرار والتسويف هذا هو الجانب السلبي للسلطة ولمفهومها هذا النوع من السلطة بالفعل سوف يؤدي إلى تتشئة غير سوية للطفل وطفل متمرد وغير قابل للتوجيه ورافض لكل ما هو قادم من أي كبير في السن أو ذو سلطة من وجهة نظر الطفل

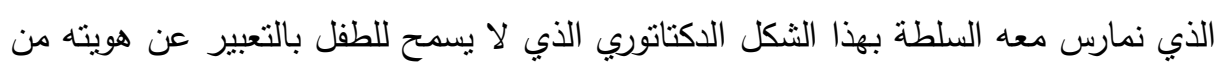
خلال التعبير عن أفكاره وعن آرائه السلبية والإيجابية.

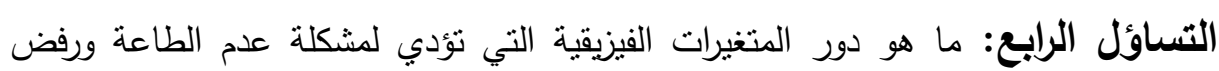

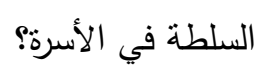
أثنتت النتائج أن المتغيرات الفيزيقية لها دورها في ظهور مشكلة رفض السلطة وعدم الطاعة طبقا لمناحي النظرية الأساسية في علم النفس البيئي منها منحنى العبني البيئي التفسير

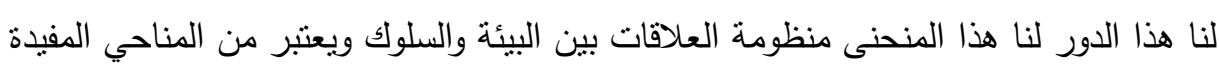

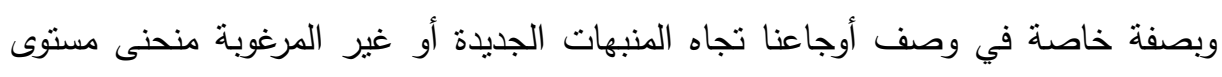

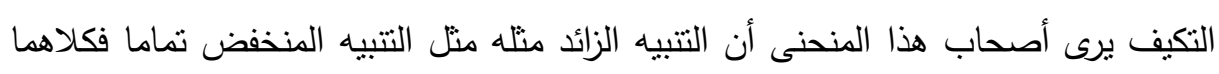

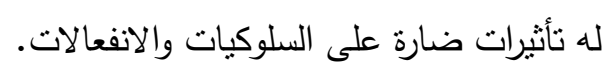
التساؤل الخامس: ما هو دور المتغيرات الفيزيقية التي تؤدي إلى مشكلة عدم الطاعة ورفض السلطة؟ وجاءت نتائج استمارة الخبراء عدم نوافر أدوات النشاط أو كراسي الجلوس أو لمبات

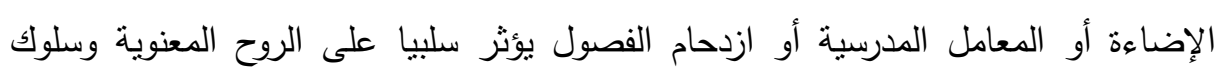
الطلاب، كثافة الفصل مرتفعة، عيوب نظام التعليم. التساؤل السادس: ما هو دور المتغيرات الإجتماعية التي نؤدي لمشكلة عدم الطاعة ورفض السلطة في الأسرة؟ جاءت الإجابات على التساؤل السادس في استمارات الخبراء مؤكدة لأهمية أساليب

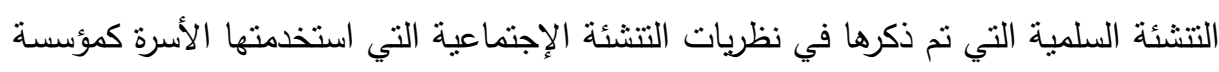

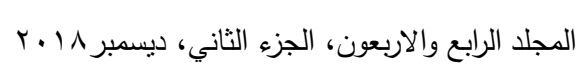




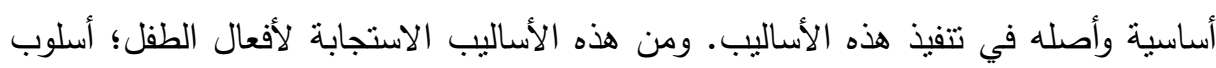

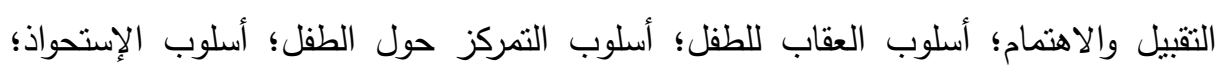

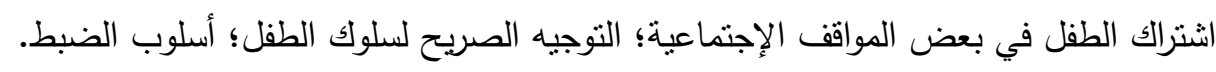

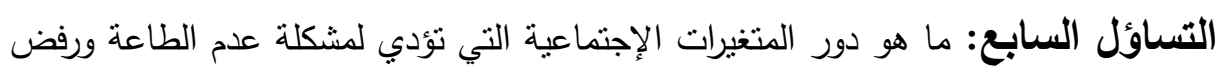

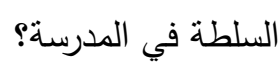

أكلت هذه الإجابات على أن دور الدرس هام جدا كمؤسسة هامة من مؤسسات التتشئة

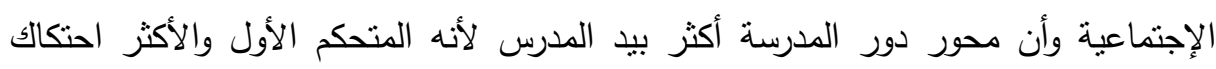

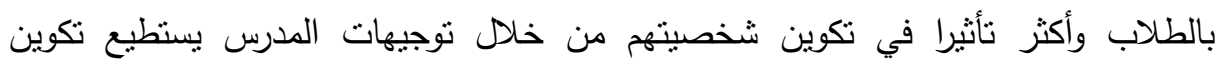

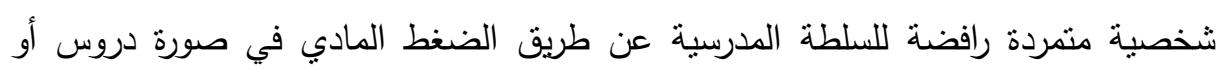

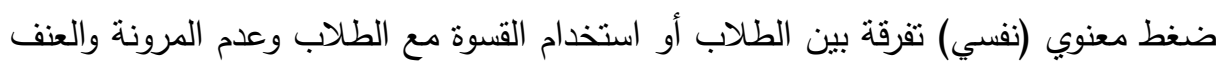

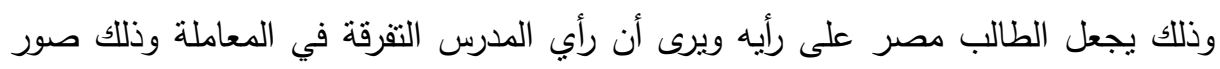
التمرد ورفض السلطة وعدم الطاعة.

التساؤل الثامن: ما هي الآثار الدترتبة على رفض السلطة وعدم الطاعة في الأسرة؛

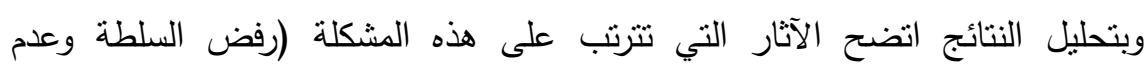

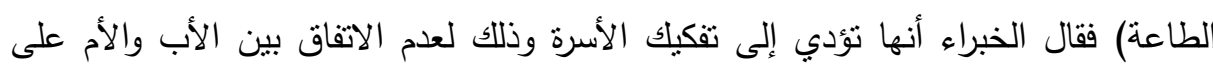

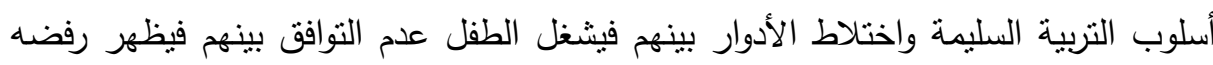

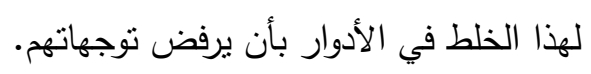
التساؤل التاسع: ما هو الدور المقترح في الأسرة لمواجهة مشكلة رفض السلطة وعدم الطاعة؟ بما أن نعد الأسرة هي المؤسسة الأولى التي تنتلى الطفل بعد الولادة وهي المؤثر الأكبر

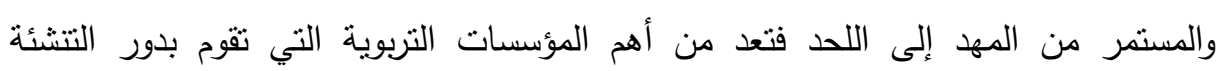

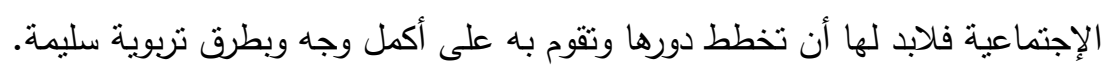

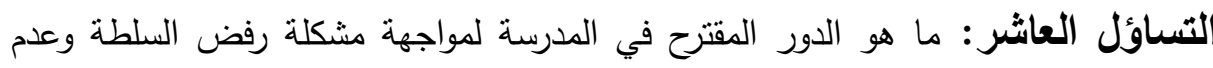

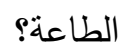


ومن تحليل النتائج رفض السلطة وعدم الطاعة فوجدنا أن الإجابات جاءت موضحة

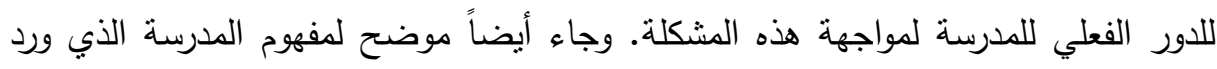
عن جابر سيد عوض وهو: هي المؤسسة التربوية التي تقوم بوظيفة تربوية ونقل النقافة المنطورة وتوفير الظروف المناسبة للنمو . التساؤل الحادي عشر: ما هو دور الإخصائي الإجتماعي لمواجهة مشكلة رفض الطاعة وعدم السلطة؟ الجانب الإنشائي والتنموي: ويتمثل في تتظيم الحباة الإجتماعية للطلاب من خلال جماعات مدرسية وإتاحة الفرص لاشتراك أكبر عدد من الطلاب جسميا ونفسيا واجتماعيا وعقليا.

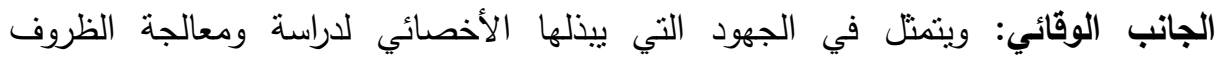
والأوضاع الإجتماعية والإنفعالية التي قد تؤثر على الطالب سلباً ووقايتهم من أسباب لفئي الإنحراف ومعاونتهم على التغلب على المشاكل والمصاعب. الجانب العلاجي: ويتمنل في مجموعة الخدمات والجهود التي يبذلها الإخصائي لمساعدة

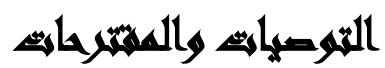

توصيات خاصة بالمنزل وأهمها: لابد أن تقوم بالتوعية المبكرة للأبوين بالوسائل السليمة للتنشئة الاجتماعية للطفل منذ بداية حمل الأم بالطفل ومدى أهميتها في التعامل مع الطفل عن طريق المراكز المتخصصة لرعاية الأمومة والطفولة. التوصيات الخاصة بالمدرسة وأهمها: لابد أن تقوم وزارة التربية والتعليم دورات تدريبية

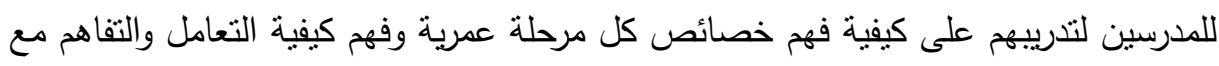
كل سن على أساس علمي وتدريبهم على كيفية توجيه الأوامر لهؤلاء الطلاب حتى لا تواجها

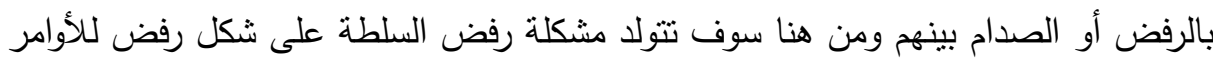

$$
\text { والتوجيهات والقواعد المدرسية. }
$$


التوصيات الخاصة بوسائل الإعلام وأهمها: إن وسائل الإعلام لها دوراً كبيراً جدًا

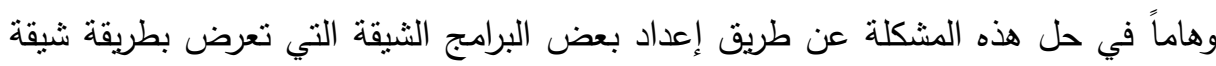

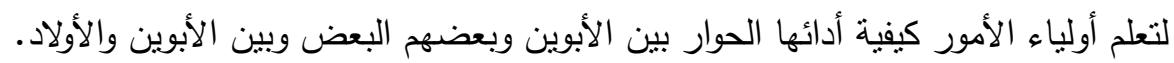

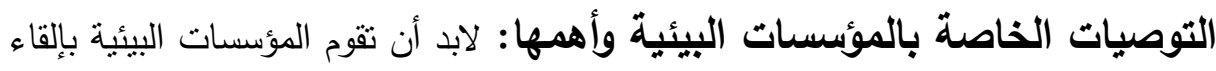

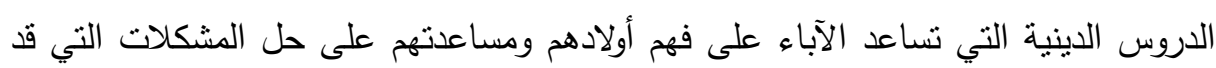
تواجه كل أسرة.

دور الحصانة القبلية للمدرسة وأهمها: لابد أن بعمل في هذه المؤسسات متخصصين

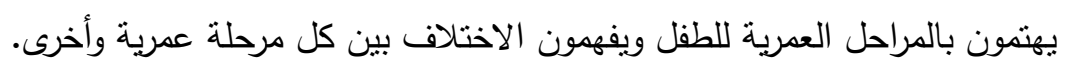

\section{المرامئم}

أحمد قاسم (فبراير، 11 ( ـ ام): المؤسسات التربوية - دورها في التتشئة الاجتماعية في أسس

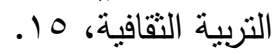

السيد عبد العاطى السيد (ب99 (19): الإيكولوجية وعلم الإجتماع الحضرى مدخل دراسة الإنسان

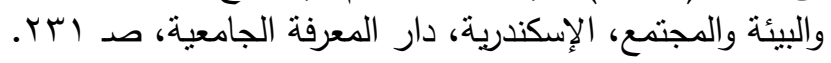

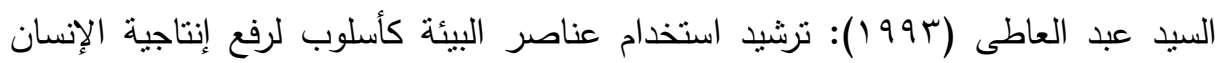

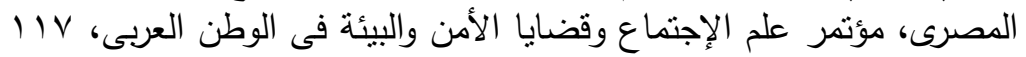

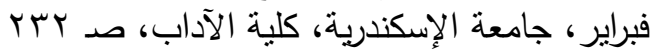

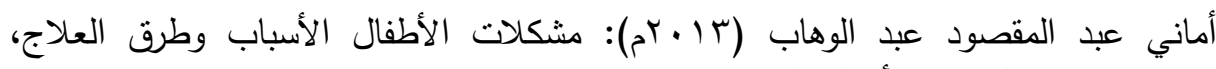

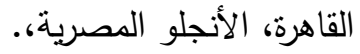

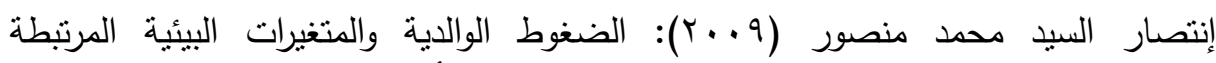

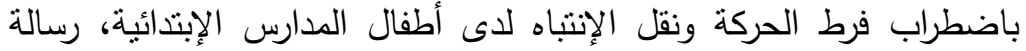

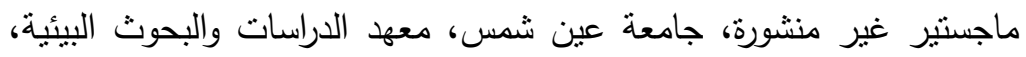

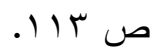

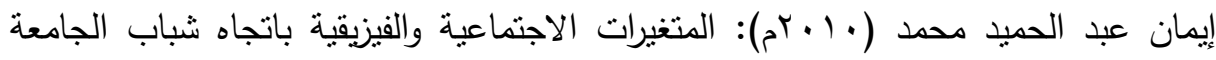

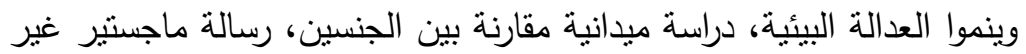

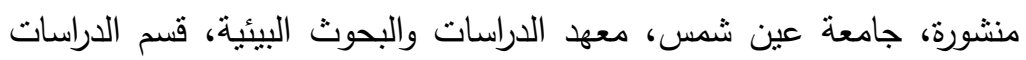
الانسانية. 


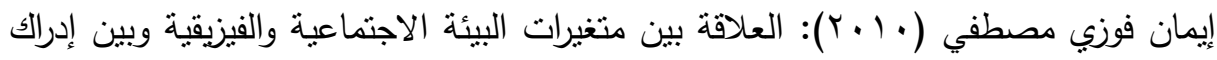

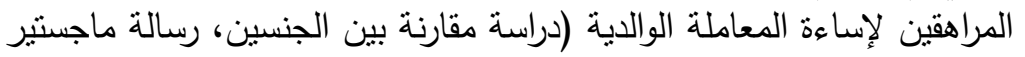

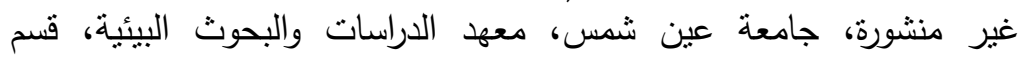

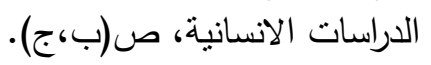

$$
\text { بسيمة وفاق (11 • r م): خمس أسباب لتمرد الأبناء على الآباء. }
$$

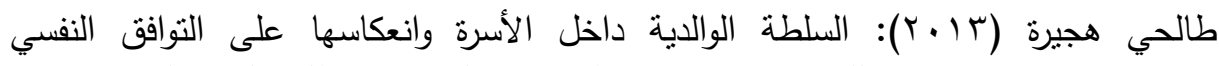

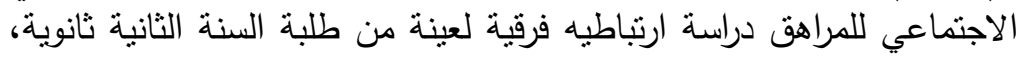

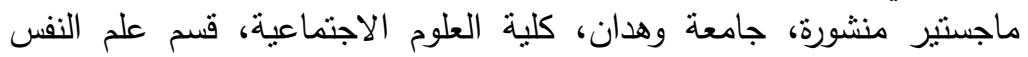

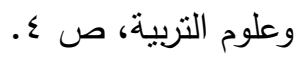

طلعت إبرهيم (799 (1): النظرية المعاصرة في علم الاجتماع، القاهرة، دار غريب للطباعة،

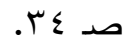

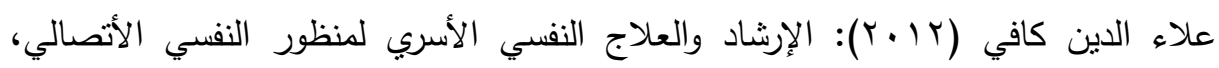

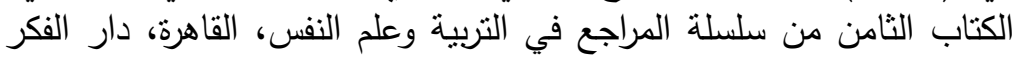
العربي.

فتحية مقحوت (ع ( ب): أساليب المعاملة الوالدية للمراهقين المتقوقين في شهادة التعليم

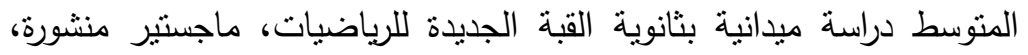

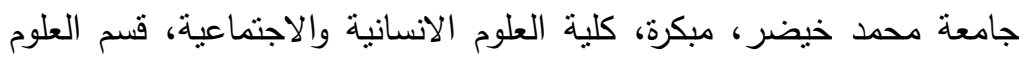

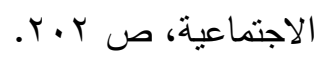

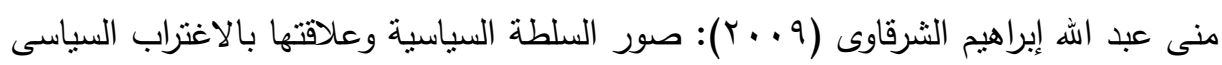

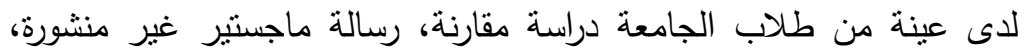

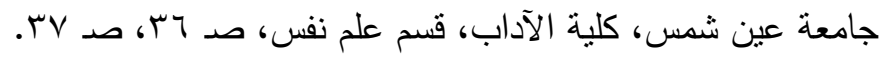

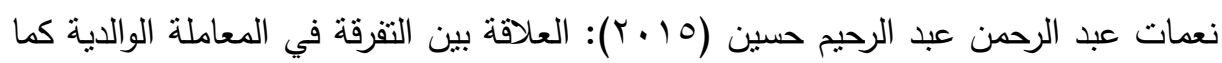

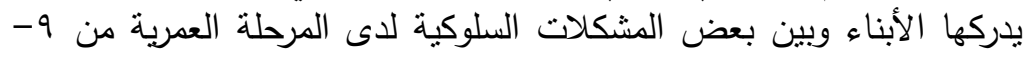

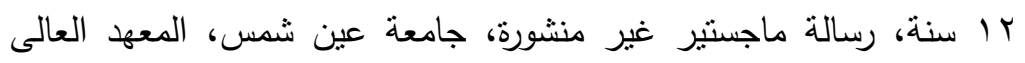

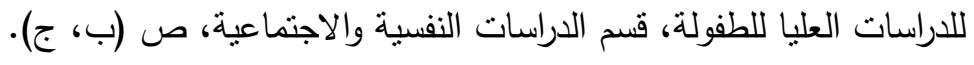

David, Bennett; Michael Lewis: Young Children Sadtustment as a Function ifmealtrea Tent, shame, and anger, child malteatmeit, vol. 10, issue, 2005.

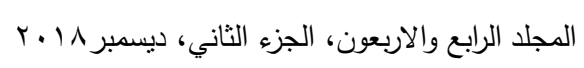


Stephen, A.; Petrelet, Natume, amd (2003): The Tram sitiontoearly ado lescence, Oxford University press.

Wilson, Robert, N. (1970): The Sociology of an Introduction, rondos hours, New York, P. 42.

THE SOCIAL AND PHYSICAL VARIABLES

ASSOCIATED WITH REFUSING AUTHORITY AND

DISOBEDIENCE

\title{
A COMPARATIVE STUDY BETWEEN MALES AND
}

FEMALES IN SOME FORMAL LANGUAGES SCHOOLS

\author{
Samah, N. Abbass ${ }^{(1)}$; M. M. A. Mahmoud $^{(2)}$
}

and Mohamed. M. M. Hassan ${ }^{(3)}$

1) Institute of Environmental Studies \& Research, Ain Shams University 2) Faculty of Arts, Ain Shams University 3) The Higher Institute for Social Work

\begin{abstract}
The researchers seek to achieve several aims by implementing this research which most important is to identify the reasons leading to the emergence of the problem of refusing authority and disobedience and the role of the social and physical variables in emergence of such problem and its consequences in the educational process; added to that, the family and school problems may result. The research also drives at identifying the role of parents as well as the occupational role of the social worker in meeting refusal of authority and disobedience. This study counts on the descriptive-analytical method using some tools such as, a two-form questionnaire by collecting data from students and experts (study sample). The researcher uses more than one theory (theory of social stress - theory of ecological system - basic theoretical aspects in environmental psychology - theories of explaining 260

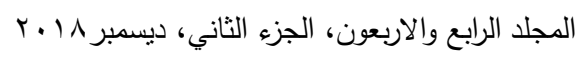


socialization process) these theories serve the topic of the study. The research sample consists of primary school students and $1^{\text {st }}$ grade preparatory stages whose ages range from 6 - 12 years old, divided into (50\% males $-50 \%$ females). The second part of the sample consists of experts of university professors, teachers, and parents to benefit from their experiences.

The research comes to several results, most important are: The physical variable is accepted for males in emergence of the problem; while females' results reject the physical variable. Regarding home or school environment, the role of the physical variable is rejected for males. For females, the physical variable is also rejected while the social variable is rejected for males and females. Concerning the social variable for home, it is accepted by males and by females, so, the role of the social variable is approved for both sexes as affecting the research problem. Regarding the role of the family and parents for meeting the problem, it is approved there is a need for using proper socialization approaches in dealing with children at home. The social worker's role is approved in his cooperation with the teaching staff for meeting the research problem at school.

The most important recommendations are crystallized in that there should be early awareness and enlightenment for parents through appropriate means of socialization of a child starting since pregnancy for its significance in dealing with a child. This can be achieved through specialized centers for motherhood and childhood care. Moreover, the Ministry of Education should hold training courses for teachers to train them how to understand characteristics of each age stage and how to deal with such a stage depending upon understanding of needs based on a scientific basis; besides train them also how to give orders to students in a way avoiding refusal or clash between them so as not to emerge the problem of refusing authority in a form of refusing orders, orientations and school rules.

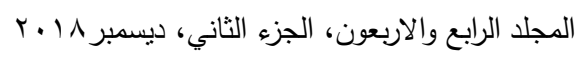

